\title{
Al and robotics in the European restaurant sector: Assessing potentials for process innovation in a high-contact service industry
}

\author{
Katharina Blöcher ${ }^{1} \cdot$ Rainer Alt ${ }^{2}$ \\ Received: 23 February 2020 / Accepted: 1 October 2020 / Published online: 18 November 2020 \\ (C) The Author(s) 2020
}

\begin{abstract}
The restaurant technology market is rapidly evolving and is transforming the restaurant business as a significant sector of tourism and hospitality. Enabled by artificial intelligence (AI), mobile apps, kiosks and chatbots revolutionize the guest experience and robots automate restaurant operations. Despite the increasing interest, the use of AI and robotics in restaurants is still in its early stage and restaurant managers are seeking guidance to leverage these technologies for service excellence. In this high-contact service sector, emotional skills need to be balanced with the possible automation potentials. The present research analyzes the current state of $\mathrm{AI}$ and robotics in the restaurant sector and proposes a systematic identification of process innovation potentials. For this purpose, a market analysis of the European AI and robotics market for restaurant operations is conducted, which yields a first knowledge base for future research and conceptual work. Besides detailed empirical data, a reference process is developed for leveraging new technologies for process innovation.
\end{abstract}

JEL classification $\mathrm{L} 86 \cdot \mathrm{O} 14$

Keywords Artificial intelligence $\cdot$ Robotics $\cdot$ Restaurant industry $\cdot$ Restaurant technology $\cdot$ Smart tourism

\section{Introduction}

The restaurant technology market is rapidly evolving and transforms the restaurant business as a significant sector of tourism and hospitality. Enabled by artificial intelligence (AI), mobile apps, kiosks and chatbots profoundly change the guest experience (Hospitality Tech 2018; Tussyadiah and Park 2018) and robots independently automate restaurant operations, e.g. Ivanov et al. 2019; Ivanov and Webster 2019. $\mathrm{AI}$ and robotics are perceived as key value drivers (Berezina

This article is part of the Topical Collection on Artificial Intelligence (AI) and Robotics in Travel, Tourism and Leisure

Katharina Blöcher

katharina.bloecher@uni-leipzig.de

Rainer Alt

rainer.alt@uni-leipzig.de

1 Leipzig University, Information Systems Institute, Grimmaische Str. 12, 04109 Leipzig, Germany

2 Leipzig University, Information Systems Institute, Grimmaische Str. 12, 04109 Leipzig, Germany et al. 2019; Ivanov et al. 2017; Mintel 2020; Oracle 2019) and experts expect the rise of these technologies to result in a wide-ranging disruption of traditional service operations and to inherit a large potential for process innovation (Bock et al. 2020; Davenport 1993; Ferreira et al. 2020). Similar to other sectors, this will transform the service industry due to effects of labor automation, productivity growth and new forms of networked service interactions between organizations, employees, and their customers (Chui et al. 2016; World Economic Forum 2018). However, the knowledge on AI and robotics is still considered low in organizations (Pumplun et al. 2019; Ransbotham et al. 2017). In particular, the technologies for restaurant operations represent a rather novel phenomenon (Berezina et al. 2019; Mathath and Fernando 2015). Companies still have difficulties in creating business value from the technological potentials of AI and robotics (Alsheibani et al. 2020; Dietzmann and Alt 2020; Hofmann et al. 2020). Moreover, restaurant managers are confronted with the question of how to manage the shift of manual tasks from service employees to technological systems, especially in times of staff shortage and growing concerns of job replacements (CUF 2018; World Economic Forum 2018). In the traditional people-driven business, they 
need to decide how human and artificial intelligence can work together "as a team" to create new forms of customer experiences and networked business interactions in restaurant ecosystems (Genysis 2017; Paluch and Wirtz 2020; Berezina et al. 2019).

In addition to the automation potential in the restaurant industry (Chui et al. 2016; CUF 2018), the service sector is also characterized by a high level of customer contact. High-contact service sectors usually require social and emotional skills to achieve excellence in hospitality, customer satisfaction and loyalty on the customer side (Prentice 2014; Prentice et al. 2020; Qiu et al. 2020). Thus, restaurateurs must be aware of the capabilities of AI and robotics technologies in substituting this human work and need to carefully decide how to deploy innovative technologies in their daily business processes. As restaurant businesses often lack any organizational IT structure (Cavusoglu 2019; Moreno and Tejada 2019), restaurant operators require specific advice on identifying opportunities and redesigning processes.

Service literature demands interdisciplinary research and conceptual knowledge that help service operators to determine the suitable technology for their purposes while considering the future collaboration between human and artificial intelligence (Paluch and Wirtz 2020; Rafaeli et al. 2017; Wirtz et al. 2018). Despite the increasing academic interest in AI and robotics in the restaurant business (Berezina et al. 2019; Ivanov et al. 2019; Mathath and Fernando 2015), a systematic assessment of opportunities for process innovation is missing in current academic literature. The research field is characterized by single case studies or experiments in lab settings, but lacks empirical data to establish conceptual knowledge as the foundation for decision support (Ivanov et al. 2019; Lu et al. 2020).

This paper aims to close this gap with a systematic view of AI and robotics technology providers that offer concrete service solutions to restaurateurs. Following the call for more research on service technologies (Kunz et al. 2019; Wirtz et al. 2018), it systematizes current service solutions using $\mathrm{AI}$ and robotics technologies and contributes to the understanding of the opportunities for process innovation in the restaurant sector. It enriches current research on $\mathrm{AI}$ and robots in service operations, which is still in its infancy and requires knowledge on how technologies impact business practices and human work (Ferreira et al. 2020; Kunz et al. 2019). Furthermore, the paper seeks to evaluate the progress of existing $\mathrm{AI}$ and robotics service solutions in performing human tasks. Even if research demonstrates the potential of AI and robotics for all human tasks in service operations (Frey and Osborne 2017; Huang et al. 2019), a quantitative view on existing technologies is missing to fully understand their capabilities, specifically in a high-contact service sector. This applies to the European restaurant sector where an empirical analysis of the European AI and robotics vendors shall offer insights to accumulate knowledge for conceptual work from a practical perspective.

For this purpose, two research questions are suggested:

RQ 1: Which opportunities for process innovation are offered by current AI and robotics service solutions in the European restaurant sector?

RQ2: How advanced are current AI and robotics service solutions in performing human tasks in restaurants' business operations?

The paper is structured as follows: The foundation part provides related research and describes the potential of AI and robotics in service processes. It also contains an overview of relevant research in the restaurant sector. After describing the methodology in section 3, the fourth section describes key results of the empirical analysis. Finally, a reference process is proposed to guide future decision processes of service managers. A detailed discussion and existing research restrictions concludes the paper.

\section{Theoretical foundations}

\section{Process innovation and artificial intelligence}

A business process is defined as "a set of logically related tasks performed to achieve a defined business outcome" (Davenport and Short 1990, p.4). Following previous research in this field, process innovation may be described as a new, efficiencyenhancing activity intended to reduce the cost of producing a good or a service (Davenport 1993; Trantopoulos et al. 2017; Un and Asakawa 2015). Process innovation may occur with any existing technology and is recognized as a key differentiator nowadays (Vom Brocke et al. 2016). To achieve process innovation in organizations, (digital) technologies are incorporated into existing business processes to increase efficiency and to remain competitive (Davenport 1993; Vom Brocke et al. 2016). However, technological functionalities must not be simply incorporated into existing business processes. Instead, these processes should be redesigned to successfully integrate novel technologies into business operations. Hence, business process and business network redesign require a high degree of business transformation and highly depend on organizational factors (Alt 2006). In this respect, employees and decision-makers need to learn how to apply novel technologies and to adopt new work routines (Damanpour and Gopalakrishnan 2001; Venkatraman 1994; Vom Brocke et al. 2016).

$\mathrm{AI}$ and robotics are increasingly important in enabling process automation and innovation in organizations (Bughin et al. 2018; Hull et al. 2015; Willcocks et al. 2015; Zebec 2019). In general, the AI-discipline engineers and deploys AI-enabled computing systems (Kaplan 2016; Simon 1995) to create machine intelligence that mimics human intelligence. Making 
machines "intelligent" requires certain abilities, such as reasoning, problem-solving, learning, communicating, perceiving, and acting (Huang and Rust 2018; Russell and Norvig 2016). Literature in this field often focuses on specific methods or techniques, such as machine learning and reinforcement learning or targets specific technologies, such as decision support systems, data mining, or big data (Nascimento et al. 2018). One promising field is the development of robots. Service robots can be described as "system-based autonomous and adaptable interfaces that interact, communicate, and deliver service to an organization's customers" (Wirtz et al. 2018, p.909). They were explored either in the form of virtual service robots (i.e. chatbots, digital assistants) or physical robots (Murphy et al. 2019; Paluch and Wirtz 2020; Wirtz et al. 2018). With the rise of big data, sensors and interconnected cyberspaces, AI applications have reached a new level: By permanently analyzing data, extracting knowledge and deducting tasks, AI technologies no longer only simulate human intelligence. Instead, the focus is on creating hybrid intelligence by combining machines and humans in networked processes (Kaplan and Haenlein 2019; Pan 2016).

When tapping into the field of AI and robotics, the identification and prioritization of opportunities in business areas is a key issue for creating process innovation (Davenport 1993; Harrington 1999; Davenport and Ronanki 2018). Use cases for business success must be identified (Davenport and Ronanki 2018) and process characteristics, e.g. knowledge intensity or required creativity, need to be considered (Davenport 2015; Seidel et al. 2015). Consequently, service organizations require a detailed understanding of how to approach new opportunities for process innovation and which technologies can perform certain tasks in their business processes (Davenport and Ronanki 2018).

\section{Al and robots in restaurant processes}

Although the application of technology in the hospitality and tourism sector is not new (Buhalis and Law 2008; Gretzel et al. 2015), the use of AI and robotics in restaurant operations represents a rather recent phenomenon (Berezina et al. 2019; Mathath and Fernando 2015). In view of the changing restaurant market, businesses have started to experiment with AI technologies and robots (Hospitality Tech 2018). Similarly, a growing interest can be observed in academic research (Berezina et al. 2019; Cain et al. 2019; Ivanov et al. 2019; Maier and Edwards 2020; Yang et al. 2020). In particular, the restaurant business has received attention from multiple research disciplines and offers promising research opportunities (Ivanov et al. 2019; Rosete et al. 2020). The adoption of AI and robotics service solutions offers a range of possibilities for process innovation in this industry (Ivanov, and Webster, C. (Eds.). 2019) and can lead to productivity growth, or improvements in customer service processes (Berezina et al. 2019;
Gretzel 2011; Ivanov et al. 2017). Especially service robots have been the subject of many articles (Murphy et al. 2019; Paluch and Wirtz 2020; Wirtz et al. 2018).

With the focus on current opportunities for process innovation, the present research screened existing literature in the Ebsco and Springer databases. Using the keywords "restaurants, artificial intelligence and robots" a narrative literature review was conducted (Rhoades 2011) to investigate possible applications of AI and robots in restaurant processes. Ivanov et al. (2019) and Ivanov and Webster (2019) provide a general overview of the applicability and effects of AI and robotics technologies in business processes. Berezina et al. (2019) also explore widely the deployment of AI and robotics and present diverse use cases for restaurants. Similarly, Cain et al. (2019) as well as Maier and Edwards (2020) describe the automation potential of AI and robotics and how this impacts business processes and the design of future service systems. As shown in Table 1, the application of $\mathrm{AI}$ and robotics in academic research ranges from datadriven table planning to sales forecasting or the development of diverse robots. Industry reports present additional applications, such as location planning, menu planning, or dynamic preparation times (Oracle 2019; Hospitality Tech 2018). In the following, only application scenarios for restaurateurs were included and solutions aimed at consumers, e.g. recommendation engines for restaurants, were not regarded in the analysis.

In sum, academic literature is often descriptive and consists mainly of case studies or prototype developments (Ivanov et al. 2019). Scholars develop scenarios for the tourism of the future or use restaurant data for their research, e.g. sentiment analysis of customer reviews. At the same time, detailed empirical data is missing due to generally low adoption rates in practice (Ivanov et al. 2019; Cain et al. 2019). Furthermore, Ivanov et al. (2019) observe a strong emphasis in the literature on the use of robots in hospitality while the potential of algorithm-based applications is often ignored or considered secondary. Finally, most application scenarios discussed by researchers take place in the US or Asia (Ivanov et al. 2017; Ivanov, and Webster, C. (Eds.). 2019; Yang et al. 2020). AI and robot applications in the European market are less in the focus or are even ignored in the (scientific) discussion. Accordingly, the examination of the European technology market of AI and robotics vendors offers novel empirical insights to develop a systematic view of current opportunities for process innovation, which may serve as a knowledge base for practitioners and researchers.

\section{Automation potential}

$\mathrm{AI}$ and robotics are becoming increasingly significant in service industries and are transforming traditional processes (Huang and Rust 2018; Paluch et al. 2020; Wirtz et al. 
Table 1 Research in the restaurant sector focusing on $\mathrm{AI}$ and robotics
Business processes

\begin{tabular}{|c|c|}
\hline \multirow[t]{6}{*}{ Customer operations } & $\begin{array}{l}\text { - Service robots and robotic waiter systems (Acosta et al. 2006; Berezina et al. } \\
\text { 2019; Claveau and Force 2019; Eksiri and Kimura 2015; Mathath and Fernando } \\
\text { 2015; Qing-xiao et al. 2010; Tzou and Kuo 2009; Yu et al. 2012) }\end{array}$ \\
\hline & $\begin{array}{l}\text { - Object detection on images for automated checkout systems (Aguilar et al. 2018; } \\
\text { Ziller et al. 2019) }\end{array}$ \\
\hline & - Operation scheduling (Nonaka et al. 2018) \\
\hline & - Delivery robots (Wang et al. 2017) \\
\hline & $\begin{array}{l}\text { - Chatbots and voice-activated technologies that enable ordering, payment or cus- } \\
\text { tomer information, e.g. Domino Pizzas DOM (Berezina et al. 2019) }\end{array}$ \\
\hline & $\begin{array}{l}\text { - Biometric identification, i.e. facial recognition integrated in self-service technol- } \\
\text { ogies: ordering, payment, preference management (Berezina et al. 2019; } \\
\text { Morosan 2011; Wu and Cheng 2018) }\end{array}$ \\
\hline \multirow[t]{2}{*}{ Reservation } & - Chatbots for reservation retrieval (Berezina et al. 2019) \\
\hline & - Data-driven table planning (Tan and Staats 2020; Vidotto et al. 2007) \\
\hline \multirow[t]{3}{*}{ Marketing } & $\begin{array}{l}\text { - The analysis of marketing campaign effectiveness based on logistic regression } \\
\text { modelling (Chen 2019; Liu et al. 2001) }\end{array}$ \\
\hline & $\begin{array}{l}\text { - Automated marketing promotion via chatbots, voice assistants, and kiosks } \\
\text { (Ivanov 2019) }\end{array}$ \\
\hline & - Customer segmentation (Sarvari et al. 2016) \\
\hline \multirow[t]{2}{*}{ Reputation management } & • Reputation management (Claypo and Jaiyen 2014; Kaviya et al. 2017) \\
\hline & $\begin{array}{l}\text { - Sentiment analyses of restaurant reviews (Beck and Libert 2017; Gan et al. 2017; } \\
\text { Kim and Song 2013; Kouvaris et al. 2018; Krishna et al. 2019; M. Govindarajan } \\
\text { 2014) }\end{array}$ \\
\hline \multirow{4}{*}{$\begin{array}{l}\text { Human resource } \\
\text { management }\end{array}$} & - Recruitment processes (Sato et al. 2019) \\
\hline & $\begin{array}{l}\text { - Shift scheduling method using planning algorithms by considering human and } \\
\text { robot tasks (Prentice et al. 2020; Tanizaki et al. 2017) }\end{array}$ \\
\hline & - Automatic labor planning in quick service restaurants (Noone and Coulter 2012) \\
\hline & - Time tracking using biometrics (Berezina et al. 2019) \\
\hline \multirow[t]{5}{*}{$\begin{array}{l}\text { Food and } \\
\text { beverage preparation }\end{array}$} & $\begin{array}{l}\text { - Analysis and development of recipes using neural networks based on recipe data } \\
\text { of combined ingredient lists, cooking instructions and food images (Herranz } \\
\text { et al. 2018; Marin et al. 2019; Salvador et al. 2017) }\end{array}$ \\
\hline & - Liquid handling control for service robots (Komoguchi et al. 2008) \\
\hline & • Cooking robots (Berezina et al. 2019; Yan et al. 2007) \\
\hline & - Beverage management (alcoholic and non-alcoholic) (Gonzalez et al. 2019) \\
\hline & • Kitchen Operation (Mathath and Fernando 2015) \\
\hline \multirow{2}{*}{$\begin{array}{l}\text { Supply chain } \\
\text { management }\end{array}$} & - Smart fridges at restaurants for automated food ordering (Ivanov 2019) \\
\hline & $\begin{array}{l}\text {-Improved inventory management and planning using time series analyses } \\
\text { (Leon-Garcia et al. 2016; Liu et al. 2001) }\end{array}$ \\
\hline \multirow[t]{3}{*}{$\begin{array}{l}\text { Management: business } \\
\text { and finance }\end{array}$} & $\begin{array}{l}\text { - Sales forecasting (Lasek et al. 2016; Xinliang and Dandan 2017) and revenue } \\
\text { management (Noone and Maier 2015) }\end{array}$ \\
\hline & $\begin{array}{l}\text { - Demand prediction and production planning in quick service restaurants (Noone } \\
\text { and Coulter 2012) }\end{array}$ \\
\hline & - Demand forecasting in restaurants (Tanizaki et al. 2019) \\
\hline
\end{tabular}

2018). On the on hand, service literature predicts that the rise of technologies will result in a massive shift of work tasks from human workers to AI-enabled technologies (Chui et al. 2016; Bughin et al. 2018; World Economic Forum 2018). Promising opportunities for human-robot collaboration, or the augmentation of service employees are discussed (Huang et al. 2019; Huang and Rust 2018; Larivière et al. 2017; van
Doorn et al. 2017). On the other hand, AI and robotics also enable a high degree of service automation and threatens traditional service jobs (Huang and Rust 2018; Larivière et al. 2017; McClure 2018). Specifically, in the food and accommodation industry, studies estimate that 75 to $85 \%$ of work activities could be augmented or replaced by AI and robotics (Chui et al. 2016; CUF 2018). 
However, the abilities of AI and robots in performing human tasks varies depending on the specific task and the required skills for mastering the activities of this task. The potential of AI technologies should not be assessed by looking at the occupation level. Instead, the activity or task level determines whether human tasks may be replaced by AI and robotics or whether technology should rather enhance human work (Chui et al. 2015; Huang and Rust 2018; Larivière et al. 2017). Usually, jobs are characterized by a range of simple and more complex tasks (Chui et al. 2015; Huang and Rust 2018). For example, Huang and Rust (2018) describe, that specific tasks require certain levels of human intelligence, i.e. mechanical, analytical, or more emotional or intuitive intelligences. Similarly, Wirtz et al. (2018) distinguish between cognitive, analytical, or social emotional work.

Generally, researchers agree that tasks with a more repetitive, homogeneous, and structured character are easier to automate through AI and robotics (Davenport 2017; Frey and Osborne 2017; $\mathrm{Lu}$ et al. 2020). This mechanical work is often routine, non-creative and unskilled labor without any required education or knowledge (Chui et al. 2015; Huang and Rust 2018; Wirtz et al. 2018). Chui et al. (2016) assume that a strong share of activities in foodservice businesses are susceptible to automation by AI due to a predictable character of most activities. In the current hospitality literature, AI and robotics technologies primarily substitute functional and repetitive tasks that lack intellectual and socio-emotional capabilities (Ivanov et al. 2019; Rosete et al. 2020). Yet, AI or automated agents have shown their ability to substitute even non-routine and more complex activities (Brynjolfsson and McAfee 2011; Frey and Osborne 2017; Huang et al. 2019). In data- and information-intensive processes, tasks may easily be supported by AI since machines have the advantage of processing a large amount of data. Some authors even believe that algorithm-based machine learning and data analytics will soon surpass humans in the decision-making of analytical tasks (Huang and Rust 2018; Paluch et al. 2020; Wirtz et al. 2018). The literature review equally identified a range of application scenarios for analytical tasks supported by AI, e.g. demand forecasting or shift scheduling (cf. Table 1).

On the contrary, human tasks are not yet affected in the same way if they require more empathetic and intuitive skills (Huang and Rust 2018; van Doorn et al. 2017; Wirtz et al. 2018). This stream of research recognizes that service robots fail to have the capability to feel and show emotions towards customers even in the near future. Robots are able to imitate human behaviors or emotional expressions (Bartneck et al. 2009; Wirtz et al. 2018) or can create a form of social presence (Belanche et al. 2020; van Doorn et al. 2017). Nonetheless, they are not yet able to develop emotional-social capabilities or authentic emotions (Paluch et al. 2020; Wirtz et al. 2018). At the same time, hospitality literature (Rosete et al. 2020; Qiu et al. 2020; Prentice 2014; Prentice et al. 2020) states that these emotional-social capabilities are particularly important in service organizations with a high level of direct customer contact (Bardzil and Slaski 2003; Walker 2017). Hospitality strongly depends on these emotional skills, such as creativity or emotional support, as employees need to manage interpersonal interactions with customers and must perform "emotional labor" to create positive customer experiences (Prentice et al. 2020; Rosete et al. 2020). Frontline service employees as "stewards of customer contact and relationship management" (Garry and Harwood 2019) require a particularly high level of such emotional intelligence (Garry and Harwood 2019; de Keyser et al. 2019). They not only create emotions on the customer side that affect perceptions of service quality and satisfaction (Rafaeli et al. 2017; Singh et al. 2017). Frontline service employees also compromise negative emotions in the service delivery process (Groth et al. 2019; Rafaeli et al. 2017).

After collecting detailed experiences with robots, hospitality firms in China even removed their service robots and are rethinking their strategy on how to use AI-based technology (Gale and Mochizuki 2019; Qiu et al. 2020). They fear that service robots erode the positive hospitality experience (Beldona and Kher 2015; Gursoy et al. 2019). Recent research proposes therefore that the ability to deliver emotional, hedonic and utilitarian aspects will be critical for robots to be successfully integrated into the service delivery process ( $\mathrm{Lu}$ et al. 2020; Rosete et al. 2020). For this reason, academic literature emphasizes the need for future research that focuses on the deployment of AI and intelligent robots adopting emotional work in the hospitality sector (Ivanov et al. 2019; Lu et al. 2020).

\section{Research methodology}

The following section provides an overview of the methodology and presents the data collection and data coding process. Current AI and robotics service solutions in the European restaurant market are analyzed that take advantage of AI and robotics technologies. The goal is to obtain insights in the current state of AI and robotics service solutions in taking over human tasks and to structure current opportunities for process innovation.

\section{Data collection}

The data sample consists of the five biggest food service markets in Europe: France, the UK, Italy, Spain and Germany (including Austria and Switzerland) (Statista 2017). The data collection took place in a multi-step approach that is presented in Fig. 1. First, a search engine approach via Google identified the results of relevant documents. For this purpose, several keywords in the respective languages were applied, i.e. 


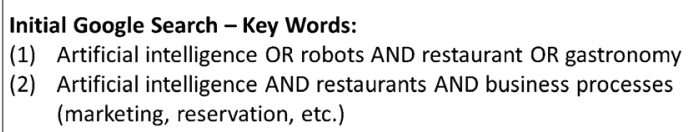

Screening of AI \& Robotics Service Solutions \& Duplicate Removing

Final Selection of AI \& Robotics Service Solutions: 99 Hits

Fig. 1 Selection process of relevant AI and robotics service solutions

artificial intelligence, robots, restaurant, gastronomy and the relevant business processes (e.g. marketing, supply chain management, reservation, etc.). After screening title and content of first results, 349 hits of corporate websites, press releases or blogs were selected that described AI and robotics service solutions in those five markets. The first selection criterion was derived from specific AI terminology, such as machine learning, robotics, algorithms, etc. As a second selection citerion, only vendors were included that specifically targeted restaurant businesses as a customer segment. Finally, studies, such as the AI 100 list 2019 (CB Insights 2020) or MMC Ventures 2019, were sighted to find additional vendors that are active in the restaurant sector. After removing duplicates, our final sample consists of $99 \mathrm{AI}$ and robotics service solutions.

\section{Data coding}

The analysis emphasized four dimensions to build first classifications. This follows prior work, which has demonstrated that the classification of service technologies can assist in building an initial knowledge base, specifically in immature service application fields (Allmendinger and Lombreglia 2005; Hunke et al. 2020; Remane et al. 2016). Therefore, systematizations may serve as a foundation for future conceptual frameworks in underdeveloped research areas (Remane et al. 2016; Hambrick 1984; Nickerson et al. 2013). In a first step, coding dimensions for a provisional coding approach were defined (Bryman 2012; Saldaña 2009) and existing conceptual work was used for this purpose (Huang et al. 2019; Kreutzer and Sirrenberg 2020; Larivière et al. 2017; Russell and Norvig 2016; Wirtz et al. 2018). Preestablished categories guided the analysis similarly to a taxonomic coding approach (Saldaña 2009) and dimensions as well as possible values for each dimension served as a codebook during the analysis. They were documented in a coding scheme along with guiding principles to be considered in the coding process (Bryman 2012). The conceptual dimensions (1) business processes and subprocesses in the restaurant sector, (2) application fields of AI capabilities (Kreutzer and Sirrenberg 2020), (3) intelligence level of tasks (Huang and Rust 2018; Huang et al. 2019) and finally (4) the role of technologies in service processes (Larivière et al. 2017; Marinova et al. 2017) are presented in the following paragraphs.

\section{Business processes and subprocesses in the restaurant sector}

In the follwowing, the business process description by Ivanov (2019) was used and relevant subprocesses were complemented following Ivanov and Webster (2019), and Moreno and Tejada (2019). This breakdown of processes was also discussed with an industry expert. These business processes and sub-processes (see Table 2) were then used to scan the sample for processes covered by AI and robotics vendors.

\section{Application fields of Al capabilities}

Following the AI literature (e.g. Russell and Norvig 2016), AI solutions should feature at least the following skills of intelligent systems: (1) natural language processing (NLP), (2.) knowledge representation, (3) automatic reasoning to identify patterns, (4) machine learning to learn from its own activities and new circumstances, (5) computer vision in the form of image analysis and processing and (6) robotics to move or manipulate objects. Nowadays, AI solutions often combine these skills in intelligent agents, service robots or digital 
Table 2 Business processes and subprocesses in the restaurant sector

\begin{tabular}{|c|c|}
\hline Business Processes & Corresponding subprocesses \\
\hline Customer operations & $\begin{array}{l}\text { Customer information, customer service incl. complain management, o } \\
\text { rder taking, consulting/selling, serving, payment, online delivery } \\
\text { management, capacity and queue management }\end{array}$ \\
\hline Reservation & Reservation retrieval, table yield management \\
\hline Marketing & $\begin{array}{l}\text { Segmentation, campaign and promotion planning, design, campaign } \\
\text { execution (across channels, e.g. Social Media, email, etc.), and } \\
\text { menu design }\end{array}$ \\
\hline Reputation management & Review management (search and reply) \\
\hline Human resource management & $\begin{array}{l}\text { Recruiting, staff planning and scheduling, staff training and } \\
\text { development, incident management }\end{array}$ \\
\hline Food and beverage preparation & $\begin{array}{l}\text { Recipe creation and menu planning, cooking and drinks, } \\
\text { kitchen device management }\end{array}$ \\
\hline Supply chain management & $\begin{array}{l}\text { Procurement planning, distributor price negotiation, } \\
\text { order/procurement management incl. administration, inventory } \\
\text { management incl. planning, controlling and food waste management, } \\
\text { quality, hygiene and food security control }\end{array}$ \\
\hline $\begin{array}{l}\text { Management: business } \\
\text { and finance }\end{array}$ & $\begin{array}{l}\text { Business strategy, forecasting and budget planning, accounting, } \\
\text { controlling and reporting }\end{array}$ \\
\hline
\end{tabular}

assistants (Russell and Norvig 2016; Wirtz et al. 2018). Especially, machine learning, automatic reasoning and knowledge representation are widely applied. Following the categorization for AI application fields of Kreutzer and Sirrenberg (2020), four application fields using these AI capabilities were defined: (1) Natural language processing (NLP), (2) computer vision, (3) robotics, and (4) expert systems. Robotics is understood in this research as the physical ability to move objects following the definition of Russell and Norvig (2016). Expert systems represent algorithm-based programs (Buchanan 1986) offering promising solutions for decision making as well as process automation and contain components for knowledge building, problem solving and communicating solutions based on machine learning (Cortez et al. 2018; Turban and Watkins 1986).

\section{Intelligence level}

As mentioned in section 2.3., different intelligence skills are necessary for diverse tasks. According to the theory of AI job replacement (Huang and Rust 2018), four intelligences exist in the context of service tasks: mechanical, analytical, intuitive, and empathetic intelligences. In their subsequent work, Huang et al. (2019) mainly distinguished between mechanical, thinking and feeling or emotional intelligences in a refined definition. Following this framework, the third dimension is used to assess the intelligence level of business processes and corresponding subprocesses. For this purpose, this research orientated on Huang et al. (2019) that analyzed the intelligence level of service tasks and used the $\mathrm{O}^{*} \mathrm{NET}$ database with about 1000 job and task descriptions to assign 41 tasks (i.e. "monitor processes, materials, or surroundings" or "thinking creatively") to the three intelligence levels. Based on these task descriptions, the tasks were assigned to the subprocesses to determine their specific intelligence level (see Table 3 and the Appendix for all subprocesses). The intelligence level of each subprocess was reviewed and challenged with a restaurant manager with more than ten years of experience to increase the validity of each assignment. This led to a total of five main intelligence levels: (1) mechanical, (2) mechanical and thinking, (3) thinking, (4) thinking and emotional and finally (5) primarily emotional subprocesses. Some subprocesses, such as human resource management: staff planning, contain diverse activities from administrative to inter-relational tasks and as a consequence require intelligences on all three levels. In these cases, the majority of tasks with a specific intelligence level defined the corresponding intelligence level of the subprocess. During the analysis, the service solution was assigned to the level of intelligence of the subprocess it supports.

\section{Role of technology in service processes (Augmentation vs. Replacement)}

Service literature describes the different role of technology in augmenting or substituting service employees (Larivière et al. 2017; Marinova et al. 2017; de Keyser et al. 2019). Technology that augments service employees assists and complements the work of humans during the service encounter and in back-of-house processes (Larivière et al. 2017; Marinova et al. 2017). If technology substitutes human work, service employees are no longer involved in the task execution 
Table 3 Assignment of tasks to corresponding subprocess and resulting intelligence level

\begin{tabular}{|c|c|c|}
\hline \multicolumn{3}{|c|}{ Business process: human resource management } \\
\hline Subprocess & Tasks & Level of intelligence \\
\hline Recruiting & $\begin{array}{l}\text { Getting information (me), scheduling work and activities/ } \\
\text { performing administrative activities (me), processing informa- } \\
\text { tion (th), interpreting the meaning of information for others (th), } \\
\text { judging the qualities of things, services or people (th), making } \\
\text { decisions and solving problems (th), communicating with per- } \\
\text { sons outside theorganization (em), staffing organizational units } \\
\text { (em) }\end{array}$ & Thinking (Th) \\
\hline $\begin{array}{l}\text { Staff planning and } \\
\text { scheduling }\end{array}$ & $\begin{array}{l}\text { Getting information (me), scheduling work and activities (me), } \\
\text { performing administrative activities (me), estimating the } \\
\text { quantifiable characteristics of products, events or information } \\
\text { (th), organizing, planning and prioritzing work (th), updating } \\
\text { and using relevant knowledge (th), coordinating the work and } \\
\text { activities of others (em), communicating with supervisors, } \\
\text { peers or subordinates (em) }\end{array}$ & $\begin{array}{l}\text { Mechanical (Me) } \\
\text { and thinking (Th) }\end{array}$ \\
\hline $\begin{array}{c}\text { Staff training and } \\
\text { development }\end{array}$ & $\begin{array}{l}\text { Coaching and developing others (em), training and teaching } \\
\text { others (em), development and building teams (em), } \\
\text { establishing and maintaining interpersonal relationships (em), } \\
\text { processing information (th), judging the qualities of things, } \\
\text { services or people (th), provide consultation and advice to other } \\
\text { (th), communicating with supervisors, peers or subordinates } \\
\text { (em), guiding, directing and motivating subordinates (em), } \\
\text { staffing organizational units (em) }\end{array}$ & $\begin{array}{l}\text { Thinking (Th) and } \\
\text { emotional (Em) }\end{array}$ \\
\hline
\end{tabular}

(Larivière et al. 2017). The fourth analysis dimension was examined to improve the understanding on how subprocesses are currently empowered by AI and robotics solutions and how vendors position the role of service solutions in association to service employees (augmentation vs. substitution).

The data set consisted of virtual documents in the form of textual descriptions of enterprise websites of AI and robotics vendors, blog articles, press releases or technical descriptions of AI and robotics vendors. This data was coded and analyzed by one author in total. In order to classify the respective AI and robotics service solutions, several coding rules were defined to minimize the effects of interpretations and to achieve consistency during the analysis phase (e.g. Bryman 2012). As shown in Fig. 2, AI capabilities were assigned by screening relevant keywords in available documents, e.g. conversational AI, automatic speech, or voice recognition for the category $N L P$. Similarly, relevant business processes and subprocesses that vendors described in the presentation of their solutions were checked to understand how they position their technology in association to service employees. To ensure the validity of the coding process, a set of $10 \%$ was additionally validated by an AI expert in an ex-post quality check. For this sample, an intercoder agreement of 98,6\% as percentage agreement and a Cohens Kappa (Cohen 1960) of 92,5\% were achieved. According to Landis and Koch (1977) this represents a strong agreement among coders which indicates the quality level of the coding process.

\section{Analysis results}

The market analysis of AI and robotics service solutions identified 99 service solutions in the European restaurant market. Technologies include AI software and robotics solutions that are offered to restaurant operators. Solutions designed for consumers were not considered (e.g. for restaurant search ). Moreover, the analysis did not distinguish between different restaurant segments. This is in line with the call of DiPietro (2017) to broaden the perspective beyond restaurant segments to reach more comprehensive results for the sector. A descriptive data analysis process was chosen as follows by counting the respective AI and robotics service solutions that correspond to the analysis dimensions.

\section{Opportunities for process innovation}

Similar to the academic literature, empirical data provides insights into the manifold opportunities for process innovation by AI and robots. Moreover, several patterns were identified of how AI and robotics solutions are currently being utilized for business processes in the restaurant sector. Vendors have developed promising solutions that often provide support for multiple processes. Back-of-house processes are specifically in the focus of technology vendors: More than half of them $(n=69)$ offer solutions for back-of-house processes. At the same time, vendors also strive to optimize the service encounter: About 55 applications aim to increase efficiency in front-of-house processes. The majority of service 


\begin{tabular}{|c|c|c|c|}
\hline $\begin{array}{l}\text { Business } \\
\text { Processes/Subprocesses } \\
\text { - Values see table } 1 \\
\text { - Coding based on the descriptions in } \\
\text { virtual documents by screening } \\
\text { relevant business processes and } \\
\text { subprocesses } \\
\text { - Multiple coding was possible as } \\
\text { vendors often support more than } \\
\text { one process }\end{array}$ & $\begin{array}{l}\text { Al Capabilities } \\
\text { - Values: NLP, computer vision, } \\
\text { robotics, expert systems } \\
\text { - Coding based on the descriptions in } \\
\text { virtual documents by screening the } \\
\text { following key words } \\
\text { - NLP: e.g. conversational Al, } \\
\text { language/speech/conversation-based + } \\
\text { Al or machine learning, speech/voice } \\
\text { recognition } \\
\text { - Computer Vision: e.g. automated vision, } \\
\text { object detection, product or meal } \\
\text { detection, OCR in combination with } \\
\text { machine learning, image } \\
\text { analysis/recognition } \\
\text { - Expert Systems: e.g. intelligent } \\
\text { algorithms, machine learning, self- } \\
\text { learning systems, Al-based software } \\
\text { - Robotics: physical robots } \\
\text { Multiple coding was possible }\end{array}$ & $\begin{array}{l}\text { Intelligence Level } \\
\text { - Values: mechanical, thinking, } \\
\text { emotional intelligence } \\
\text { - Coding based on the associated } \\
\text { intelligence level of the subprocess } \\
\text { that is addressed by the vendor } \\
\text { - The level of the subprocess was } \\
\text { identified by the assignment of tasks } \\
\text { on different intelligence levels using } \\
\text { the classification of Huang et al. } 2019 \\
\text { - see Appendix }\end{array}$ & $\begin{array}{l}\text { Role of technology } \\
\text { - Values: augmentation, substitution } \\
\text { - Coding based on descriptions in } \\
\text { virtual documents by screening the } \\
\text { following keywords } \\
\text { - Augmentation: e.g. assistance, } \\
\text { employee support, enhancement of } \\
\text { employees' work, improved decision } \\
\text { making } \\
\text { - Substitution: e.g. self-service, fully- } \\
\text { automated, autonomous, fully } \\
\text { technology provided }\end{array}$ \\
\hline
\end{tabular}

Fig. 2 Coding dimensions, classification rules and data sources within the coding process

solutions $(n=84)$ are related to the processes customer operations, management: business and finance, human resource management and food and beverage preparation (see Table 4).

By analyzing the application fields of AI capabilities (NLP, computer vision, robotics, expert systems), it becomes evident that certain capabilities and functionalities are applied more frequently in certain business processes (see Table 5): Expert systems are prominently used by AI and robotics vendors: 35 identified solutions primarily take advantage of algorithmbased machine learning in the form of expert systems. Specifically, in back-of-house processes AI service solutions are present as expert systems in human resource management or business and finance operations. Here, analytical tasks of the sector are supported in sales, demand or even cash-flow forecasting as well as in staff planning activities. Expert systems are also in use for error and anomaly detection (e.g. Unox, Megara) or the generation of recommendations for customer operations (e.g. Dynamic Yield) .

As in other sectors, conversational agents in the form of chatbots or voice-activated assistants are growing in popularity (e.g. de Keyser et al. 2019; Berezina et al. 2019; Adam et al. 2020). With a large amount of different service solutions, NLP especially transforms front-of-house processes, such as customer operations and reservation processes. AI-enabled solutions enable immediate assistance at all times and consistency in communication (Berezina et al. 2019). Chatbots allow the ordering of menu items or the reservation of tables or provide valuable information. Besides the automation of service communication, NLP is also used for analytical purposes, e.g. to analyze user comments in reputation management. In back-of-house solutions, NLP still plays a minor role. A few service solutions strive to help restaurateurs in recruiting or in monitoring staff communication (e.g. Quapa, Aggity HR) or assist in procurement processes, such as the Matcha Wine chatbot . Further interesting NLP applications include Crystal AI, which aids in business and finance management by providing key metrics for managers using a conversational approach.

In contrast to the high interest in academic literature, only 15 robotics vendors were found. As already mentioned by Berezina et al. (2019), robots have so far created more opportunities in back-of-house processes. Their deployment can reduce time for preparation and cooking or increase
Table 4 Number of AI and robotics service solutions in business processes of the restaurant

\begin{tabular}{lll}
\hline & Business process & Number of service solutions \\
\hline Front-of-house processes $n=55$ & Reputation management & 6 \\
& Marketing & 7 \\
& Reservation & 13 \\
& Customer operations & 29 \\
Back-of-house processes $n=69$ & Management: business and finance & 17 \\
& Supply chain management & 14 \\
& Food and beverage preparation & 22 \\
& Human resource management & 16 \\
\hline
\end{tabular}


Table 5 Number of AI and robotics service solutions in business processes using AI capabilities

\begin{tabular}{|c|c|c|c|c|c|}
\hline & Business process & Natural language processing & Computer vision & Expert systems & Robotics \\
\hline Overall & & 36 & 23 & 35 & 15 \\
\hline \multirow[t]{4}{*}{ Back-of-house processes } & Customer operations & 13 & 11 & 4 & 6 \\
\hline & Reservation & 11 & 0 & 2 & 0 \\
\hline & Marketing & 5 & 0 & 1 & 1 \\
\hline & Reputation management & 6 & 3 & 0 & \\
\hline Back-of-house processes & Overall & 35 & 14 & 7 & 7 \\
\hline \multirow[t]{4}{*}{ Back-of-house processes } & Human resource management & 3 & 0 & 13 & 0 \\
\hline & Food and beverage preparation & 3 & 3 & 6 & 13 \\
\hline & Supply chain management & 2 & 5 & 7 & 1 \\
\hline & Management: business and finance & 3 & 4 & 11 & 0 \\
\hline Back-of-house processes & Overall & 11 & 12 & 37 & 14 \\
\hline
\end{tabular}

consistency in food quality or productivity (Berezina et al. 2019). Around 14 robotics vendors (e.g. Da Vinci Kitchen, Cala, or Realtime Robotics) market robots that prepare cocktails or draw beer or create diverse meals, such as burgers or pizza. However, a mere seven robotics vendors are active in front-of-house processes, e.g. in serving and order taking, which is in contradiction to the intense research focus on the interaction between robots and customers (e.g. Lu et al. 2020; Qiu et al. 2020; van Doorn et al. 2017). In this line, industry experts declared that the adoption of service robots in customer processes will take more time than adopting industrial robots due to the range of human intuitive and emotional qualities required in service industries (Berezina et al. 2019; Murphy et al. 2019).

Finally, computer vision capabilities are most often incorporated in innovative self-service checkout systems in customer operations. Especially in canteen settings, pre-set food is scanned and payment subsequently automated (e.g. Auvisus or Gastrobotics). Another promising use case is food waste reduction within the supply chain, which has become a key topic for restaurants and vendors. For example, Winnow Vision or Kito, have created innovative solutions to enhance sustainable business practices. Furthermore, image analyses have been successfully combined with NLP in reputation management (e.g. Cloudreputation or Travelappeal). However, biometrics, e.g. in the form of facial recognition has not yet established itself in Europe despite its anticipated potential (Berezina et al. 2019; Oracle 2019). Here, only one solution was detected. Similarly, the use of recipe databases is currently not widespread. Only four AI vendors were active in this field, although first solutions, such as IBM Chef Watson were already developed quite early (IBM 2015).

The deployment of different AI capabilities leads to a divergent role of technology in the redesign of traditional processes. Table 6 demonstrates that the prominent use of conversational agents, self-service technologies and a few robots has the effect that AI and robotics services strongly seek to substitute service employees in the service encounter. 42 vendors position their solutions in a way that $\mathrm{AI}$ and robotics services replace the responsibilities of service employees in front-of-house processes. On the contrary, the strong share of expert systems in back-of-house processes is associated with a stronger augmentation of service employees (58 service solutions).
Table 6 Role of technology in service processes: substitution or augmentation of service employees

\begin{tabular}{llll}
\hline & Business process & Substitution & Augmentation \\
\hline Front-of-house processes & Reputation management & 0 & 6 \\
& Marketing & 5 & 4 \\
& Reservation & 11 & 3 \\
& Customer operations & 26 & 2 \\
& Overall & 42 & 15 \\
Front-of-house processes & Management: business and finance & 0 & 17 \\
& Supply chain management & 1 & 14 \\
& Food and beverage preparation & 11 & 11 \\
& Human resource management & 0 & 16 \\
& Overall & 12 & 58 \\
\hline
\end{tabular}


To summarize, different capabilities are deployed by vendors for different business processes with the effect that restaurant operators must take various decisions when redesigning service processes. Functionalities implemented in these information systems strongly impact the redesign of processes and tasks (Davenport and Short 1990; Davenport 1993). Moreover, the diverse capabilities of AI and robotics service solutions affect the future role of service employees so that service managers must need to be aware of these capabilities to successfully design future AI-enabled operations.

\section{Substitution of human tasks by $\mathrm{Al}$ and robotics}

Related to the second research question, the progress of technologies in substituting human tasks was analyzed. The theory of job replacement by Huang and Rust (2018) argues that AI will ultimately take over all human tasks on all intelligence levels - from more mechanic to emotional labor. This research strives to provide further empirical data in association with the theory, especially in a high-contact service industry where emotional labor plays a significant role to achieve hospitality (Prentice 2014; Prentice et al. 2020; Rosete et al. 2020).

Table 7 provides an overview of AI and robotics service solutions that have developed solutions for certain subprocesses. Like the results of Chui et al. (2016) a high amount of subprocesses were discovered that require a lower intelligence level and that are automated more easily. Similarly, 94 of all solutions support or execute tasks in subprocesses on a lower intelligence level (mechanical/mechanical-thinking) in comparison to only 24 solutions that assist in thinking and emotional tasks. This is in line with the job replacement theory (Huang and Rust 2018), which expects AI to first replace tasks on the mechanical and thinking level. Solutions that assume tasks on the mechanical level refer to accounting, ordering, serving, and payment or cooking and drinks. Subprocesses with additional thinking tasks often represent analytical or coordinating activities, such as staff planning, sales forecasting, or controlling.

When investigating the application fields of AI capabilities (see Table 8), it becomes apparent that mechanical processes are mainly supported by robotics and conversational agents using NLP. Physical robots were only found in subprocesses with a higher intelligence level. In subprocesses with a high amount of mechanical and thinking tasks, particularly expert systems were applied to assist employees. In emotional-thinking subprocesses, a few AI services implemented NLP to support the business strategy development and the reputation management in combination with computer vision technologies. Expert systems were also occasionally deployed for processes with a higher intelligence level.

Again, the analysis of the specific role of technologies in supporting or augmenting human employees additionally confirms the theory of Huang and Rust (2018). AI and robotics service solutions that support subprocesses and tasks on a mechanical level are intended more to replace human work whereas the look at subprocesses with thinking and emotional tasks reveals that most solutions still augment service employees in service process. This could indicate that the development of technologies is not yet as advanced and that the restaurant industry, as a contact-intensive service sector, is at an early stage of the AI evolution.

Nevertheless, about 24 vendors already offer solutions that perform or support analytical and emotional tasks. This contradicts current hospitality literature (e.g. Ivanov et al. 2019; Rosete et al. 2020) which states that AI and robotics are mainly used for functional, repetitive tasks in hospitality processes that lack intellectual and socio-emotional capabilities (Ivanov et al. 2019; $\mathrm{Lu}$ et al. 2020; Rosete et al. 2020). Solutions that support subprocesses on the thinking level are currently concerned with recipe creation combining different ingredients and flavors based on large recipe databases. Single AI service solutions are integrated in self-service solutions and take over the consulting and selling to the customer. Further service solutions were identified in back-of-house processes, i.e. staff training and development. The vendor Aggity, for example, has developed, the "Talent Management Service" for staff development by analyzing employee profiles, monitoring employee development, and automatically identifying risk candidates through algorithms. This example indicates that emotional labor does not only take place in the service encounter. Instead emotional intelligence also plays a significant role in back-of-house processes in the restaurant sector.

Figure 3 combines the analysis dimensions and offers an overview of the potential of process innovation in the respective business processes along with the role of technology and the different intelligence levels of subprocesses. It shows the number of $\mathrm{AI}$ and robotics solutions by means of pictograms and indicates that the potential of process innovation using $\mathrm{AI}$ and robotics technologies strongly depends on the respective business processes. For some business processes, AI and robotics vendors offer more $\mathrm{AI}$ and robotics service solutions, resulting in different levels ${ }^{1}$ of opportunities for process innovation: In processes, such as customer operations and food and beverage preparation, the potential for innovation is higher whereby processes, such as marketing, and reputation management are on a lower level. When tapping into the field of $\mathrm{AI}$ and robotics, the identification and prioritization of use cases in business processes is a key issue for creating process innovation (Davenport and Short 1990; Davenport 1993; Davenport and Ronanki 2018). Service operators should therefore consider the progress of technologies in specific business processes and their level of potential innovation while identifying the appropriate use case for their

\footnotetext{
${ }^{1}$ However, the processes under consideration contain a different number of subprocesses (see Table 1) so that a different level of technology advancement could also be biased by the number of subprocesses and related opportunities.
} 
Table 7 Service solutions categorized by intelligence level, business processes \& role of technology

Intelligence level of subprocesses

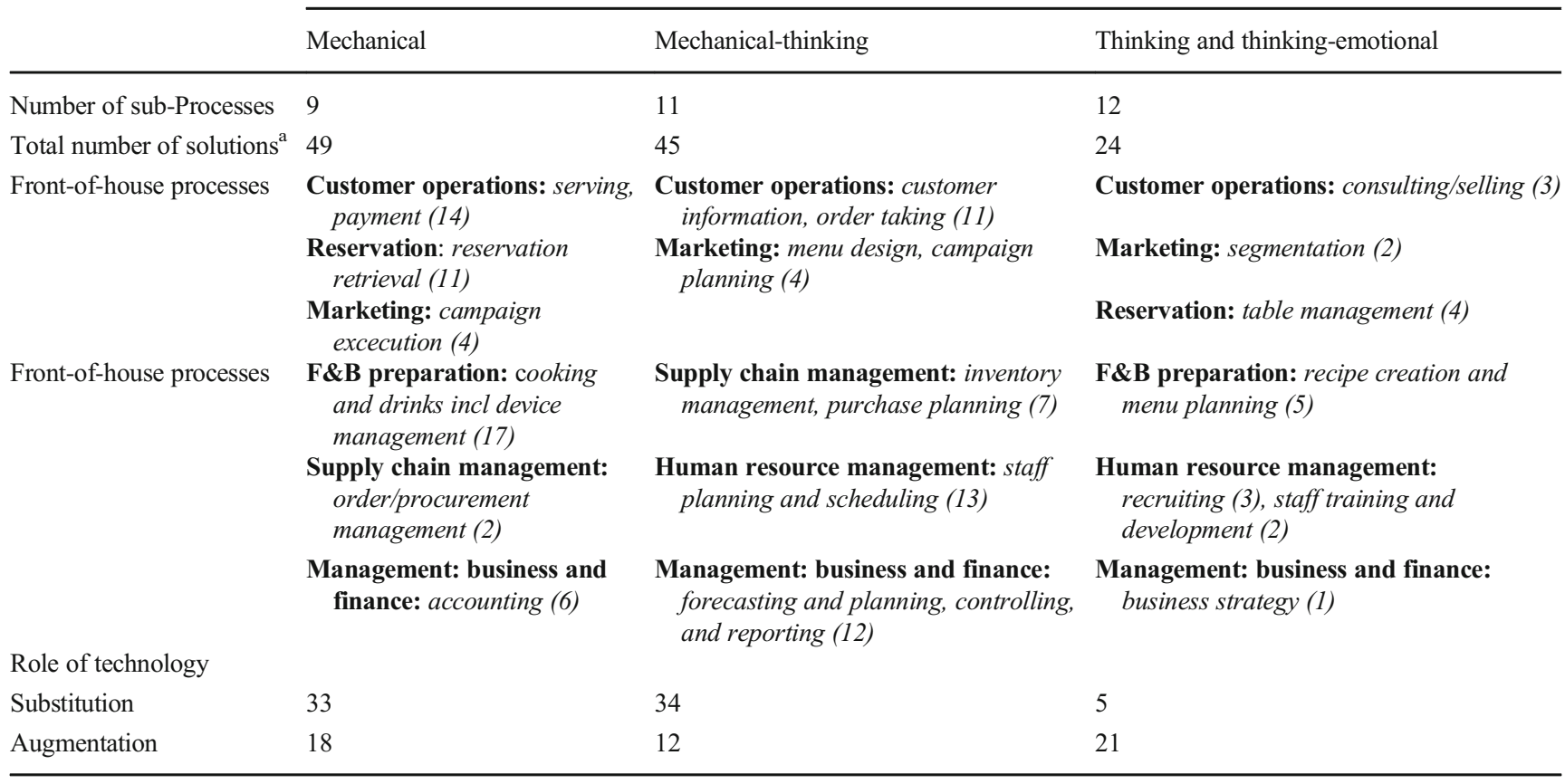

${ }^{a}$ As AI and robotics service providers can support multiple subprocesses, multiple categorizations are possible.

business. Moreover, the future role of technology strongly depends on the intelligence level of the respective subprocesses so that restaurant operators should incorporate the intelligence level into their considerations as well.

\section{Decision support for service managers}

In reference to the research questions, the market analysis generated empirical data for a systematic view on opportunities for process innovation in the restaurant sector and the advancements of AI and robotics service solutions in a high-contact service sector. At the same time, such a systematization of service solutions may serve as the foundation for future conceptual work that supports the industry in strategic decision making.
Service managers need to determine whether and when to benefit from AI and robots that feature a particular intelligence (Huang and Rust 2018). They should also conduct a thorough analysis of alternatives to develop a coordinated plan before redesigning their processes (Venkatraman 1994; Davenport and Ronanki 2018). Decision support can thereby assist service managers in finding the adequate technology and in redesigning future processes for the collaboration of human and artificial intelligence (Larivière et al. 2017; Paluch and Wirtz 2020; Wirtz et al. 2018). At the same time, the review of hospitality and service literature demonstrated that only little research developed conceptual guidance to support service managers in their decision process and future task allocation (Belanche et al. 2020; Huang and Rust 2018; Larivière et al. 2017; Paluch et al. 2020; Wirtz et al. 2018).
Table $8 \mathrm{AI}$ and robotics service solutions categorized by AI capability and supported subprocesses

\begin{tabular}{lllll}
\hline AI capability & \multicolumn{2}{l}{ Intelligence level of subprocesses } & Thinking & $\begin{array}{l}\text { Emotional- } \\
\text { thinking }\end{array}$ \\
\cline { 2 - 5 } & Mechanical & $\begin{array}{l}\text { Mechanical- } \\
\text { thinking }\end{array}$ & 4 & 8 \\
\hline Natural language processing & 16 & 16 & 0 & 1 \\
Computer vision & 18 & 5 & 7 & 3 \\
Expert systems & 6 & 21 & 0 & 0 \\
Robotics & 14 & 2 & & \\
\hline
\end{tabular}




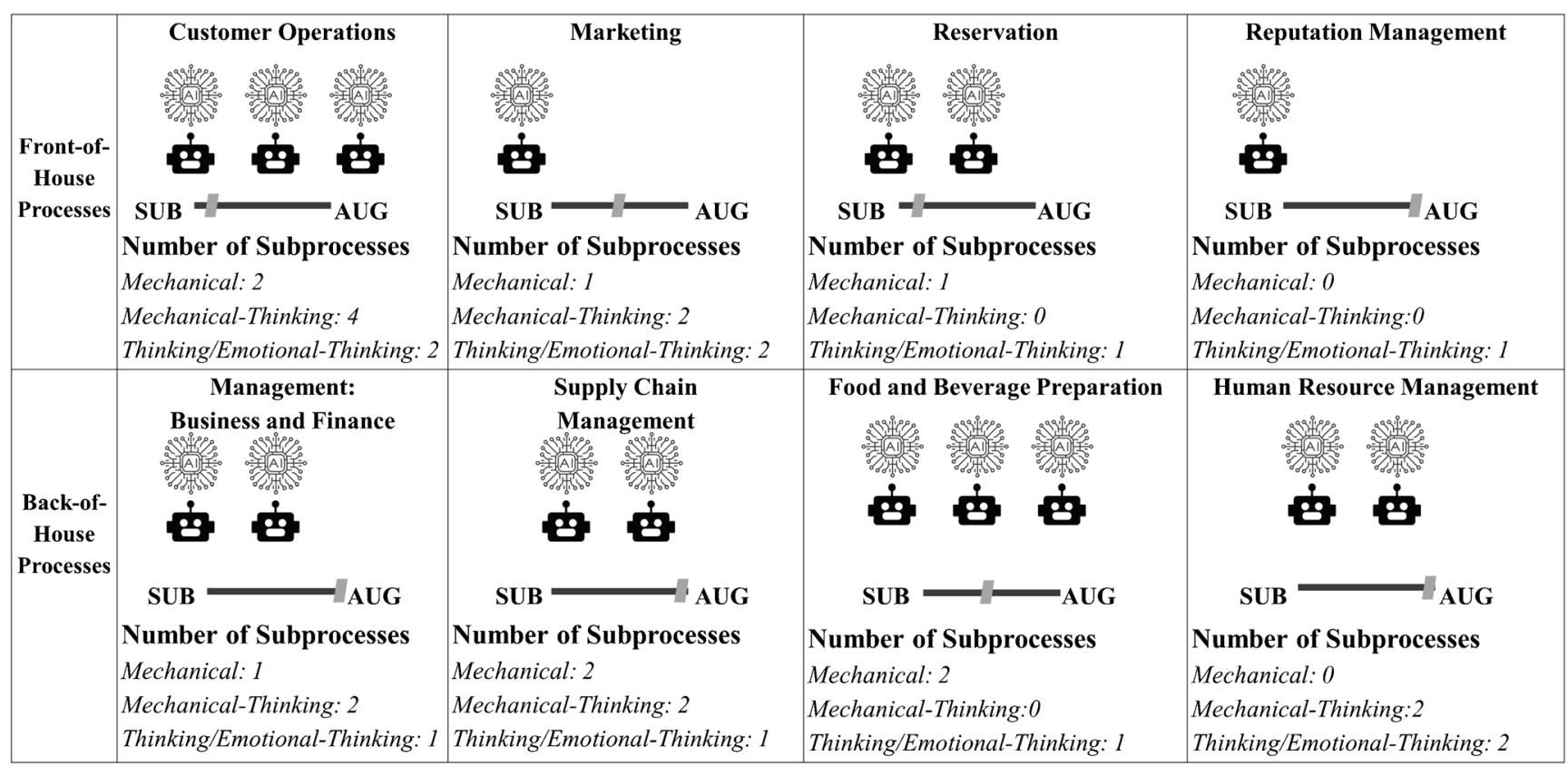

Fig. 3 Number of service solutions, the role of technology, and the intelligence level of subprocesses

This research postulates that process innovation represents a valuable perspective to integrate a process view with the systematic identification of innovation opportunities (Davenport and Short 1990; Davenport 1993). Simultaneously, the business process perspective has the purpose of planning and coordinating operational tasks, clarifying responsibilities and aligning IS technologies to (service) employees (e.g. Davenport 2015). Thus, a perspective on business processes should be adopted that structures the application domain of AI and robotics in service operations and coordinates tasks along business operations.

Previous conceptual work, e.g. the service deployment model, focuses on the nature of tasks as the decision criteria for future task allocation (e.g. Huang et al. 2019; Huang and Rust 2018; Wirtz et al. 2018). Yet they fail to relate tasks and activities to specific business processes. This is important since service managers first need to identify specific opportunities for improvements to consider the use of new technologies. Looking at service solutions in the context of business processes facilitates the identification of use cases and may guide service managers where to start with applying AI and robotics. Therefore, this contribution proposes an integrated view on business processes and the nature of tasks as the foundation for conceptual models. Following the work of Davenport (1993), it suggests a reference process for the selection of $\mathrm{AI}$ and robotics technologies that is demonstrated in Fig. 4.

First, the business requirements and the appropriate use case for AI service solutions need to be identified in specific business processes, e.g. in the subprocess of staff planning in human resource management. Afterwards, service operators, such as restaurant managers, should define the task portfolio of a subprocess and the level of intelligence, e.g. creating a shift plan. In step 3 and 4, necessary functionalities and AI capabilities of available service solutions, e.g. NLP, will be examined in greater detail and mapped with the corresponding business need (e.g. Hofmann et al. 2020), e.g. optimizing the shift planning. Moreover, service managers are advised to consider strengths and weaknesses of technological capabilities and related consequences for the redesign of processes (Davenport and Short

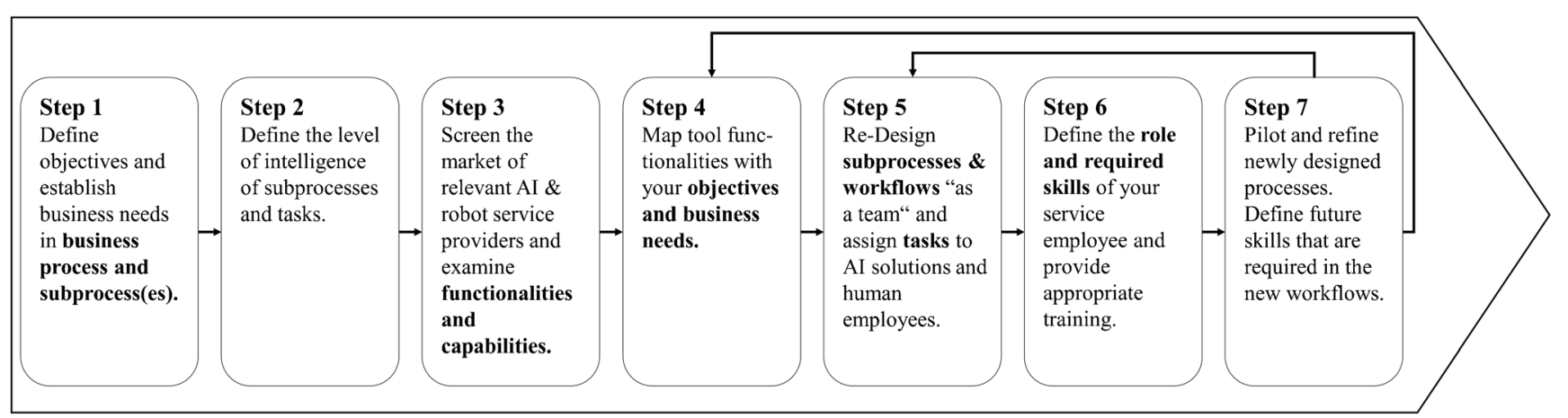

Fig. 4 A reference process for selecting and implementing AI and robot service solutions 
1990; Davenport 1993; Davenport and Ronanki 2018). The fifth step addresses the discussion of whether human abilities are still required for the specific task, for example for communicating shifts that are not fitting the indicated timings of employees. Similar to the service deployment model (Paluch et al. 2020; Wirtz et al. 2018), the type of task and its intelligence level defines whether AI or robotics should take over the respective activity or if human and artificial intelligence should collaborate. Humans collaborate with robots and AI, which augments their abilities in high complex analytical and cognitive work settings (Larivière et al. 2017; Paluch et al. 2020; Wirtz et al. 2018). On the contrary, service employees may assist robots or conversational agents, e.g. in sustaining their functionality. Service managers must think of new tasks for service employees as well as creative workflows of human-robot collaboration. Restaurant operators should consider that AI and robotics are also suspect to technical problems. Therefore, new tasks, such as error handling of technologies and robot maintenance arise in processes (Berezina et al. 2019; Ivanov and Webster 2019).

If subprocesses and workflows are more complex, Davenport (2018) suggests using design thinking methods to develop new workflows together with customers and employees. In these redesigned processes, employees require a clear understanding of their novel roles associated with the rising infusion of $\mathrm{AI}$ and robotics technologies (Larivière et al. 2017; Lu et al. 2020; Paluch et al. 2020). Novel processes driven by human-robot collaboration offer new responsibilities for service employees, but also complicate the roles of employees, which can result in stress for employees and deviation from newly prescribed processes (Belanche et al. 2020; Christ-Brendemühl and Schaarschmidt 2019). Consequently, managers should prepare their service employees and provide appropriate training. This will allow employees to feel empowered and motivated to meet their new responsibilities (Larivière et al. 2017; Maier and Edwards 2020). The final step consists of piloting the solution: Service operators, such as restaurant managers, should test the AI service solution along with newly defined workflows (e.g. Davenport 1993). If functionalities or the workflow itself are not yet satisfactory, iterations should follow like known from agile methodologies. This piloting phase also offers opportunities to learn about new skills that are required for the new workflow.

\section{Contributions}

Driven by the technological progress of AI technologies, staff shortage, and productivity growth, experts from industry and research expect the rising adoption of AI technologies and the transformation of all service sectors, including the restaurant sector. In accordance with the call for more research on service technologies (Kunz et al. 2019; Wirtz et al. 2018), this paper analyzed the current European market of AI and robotics service solutions in the restaurant business as a highcontact service sector. Current solutions were screened to generate empirical data for a systematic view on AI and robotics opportunities for process innovation in restaurants. The paper not only provided empirical evidence for the theory of job replacement (Huang and Rust 2018). It also described the characteristics of existing AI and robotics solutions to create a foundation for conceptual work in the field. Four main contributions shall be mentioned:

First, the vertical analysis of a single service sector provides empirical data on how existing AI and robotics technologies already perform human tasks corresponding to business processes and tasks in a high-contact service industry. By taking the restaurant service sector as an example, an early transformation stage of the service sector was investigated. Similar to existing literature (Chui et al. 2016; CUF 2018; Ivanov et al. 2019), the analysis demonstrates that a broad range of subprocesses and tasks in the restaurant sector require skills on a mechanical intelligence level and that the majority of identified AI and robotics service solutions currently assume these activities. Nevertheless, the analysis also identified that about $24 \%$ of the solutions assume intellectual or emotional tasks. Even if the quality of these solutions is not assessed in this research, the evolution is already visible that even high-contact service sectors containing emotional tasks will be increasingly overwhelmed by AI technologies. Thus, service operators will be confronted more often with the decision of whether existing service solutions are appropriate for the specific tasks and should strike the appropriate balance between automation and human contact.

Second, with regard to conceptual frameworks, a reference process was proposed to provide first practical guidance: As service literature on the interplay of AI technologies and organizational structures is still in its infancy, the suggested reference process aims at offering entry points for future research. Furthermore, empirical data were provided as the foundation for further conceptual work that can guide service operators in their decisions. In this nascent field, a first knowledge base for future systematization approaches was suggested, which might serve the development of archetypes (e.g. Remane et al. 2016). The combination of analysis dimensions could, for example, examine the maturity level of AI and robotics solutions in subsequent research. Early results indicate that such a maturity level may depend on the type and the number of processes being supported and that about $30 \mathrm{AI}$ and robotics service solutions already provide assistance in multiple business processes and subprocesses. Moreover, the deployment of a mix of different AI capabilities also direct to a certain maturity level of AI service solutions. To attain autonomy, robots incorporate, for example, further capabilities, such as image recognition or NLP (Murphy et al. 2019). The Barney Bar from FP Robotics represents such an example that has integrated NLP abilities allowing the customer to directly 
order from the robot. Future research can continue from this state and examine the maturity level of AI and robotics solutions as a basis for future decision support. Additional analysis dimensions, such as the potential for networked business operations in the restaurant's ecosystem could be relevant. The analysis of platform aspects, i.e. the multi-sidedness, transaction processes or the creation of network effects (Cusumano et al. 2019; Evans and Schmalensee 2016; Alt 2020) can point to the economic stability of solutions and thus represent additional indicators for their maturity. Some service solutions are provided directly by platform providers, such as Open Table, Quandoo or Trip Advisor (La Fourchette). In addition, vendors, such as Matcha Wine, Cortilla or Quapa have created own platform approaches that strive to connect restaurateurs with different stakeholders. The focus on platform aspects may also point to automation potentials between business partners in the restaurant ecosystem, e.g. with restaurant suppliers. Finally, such systematization approaches could not only assist service operators in identifying use cases for process innovation. They could offer guidance for the prioritization of certain technologies based on existing strengths and weaknesses and could be used in future methods to assess the potential of AI and robotics technologies.

Third, a lack of specific research in academic literature opens entry points for future research. Despite the strong emphasis on the service encounter in academic research, the large number of back-of-house solutions highlights the necessity to look at opportunities in all business processes. Back-of-house processes require more attention in academic research, specifically in relation to emotional work (Tambe et al. 2019) and promising potentials of automation and co-creation in networked service systems (Bock et al. 2020). Conceptual work should consider both the service encounter and the back-of-house processes to develop comprehensive guidance for service operators. Furthermore, the intense use of machine learning and automatic reasonings specifically in the application of expert systems underlines the necessity to extend future AI research in the hospitality sector. Besides social and virtual robots, research needs to integrate these applications in their conceptual work. Rosenblat and Stark (2016) as well as Lee et al. (2015) demonstrate, for example, how the use of algorithms for work assignment negatively influences the collaboration between employees in service processes. Inadequately implemented AI service solutions resulted in decreased employee retention and satisfaction in business operations (Lu et al. 2020; Prentice et al. 2020) so that these aspects must be included in the conceptual work for comprehensive decision support.

Finally on the practical side, the analysis reveals several potentials for future AI services as well as opportunities for (new) AI technology providers: First, regardless of large datasets and research in this field (Herranz et al. 2018; Marin et al. 2019; Salvador et al. 2017), commercial applications that combine image and text data for creating recipes are rare. Second, compared to other sectors, AI service solutions are little present in the restaurant's marketing processes. For example, this refers to automatic content creation. Instead, the MMC Venture report 2019 demonstrated that around $25 \%$ of all identified AI solutions in Europe are developed for marketing teams. In contrast, the present analysis only detected 14 AI solutions (11\%) that facilitate marketing and reputation management activities. Moreover, robotics or voice-activated agents that create human-artificial cocreation in the kitchen or optimize internal communication were rarely found.

\section{Research limitations}

The primary research objective was the analysis of the current market situation for $\mathrm{AI}$ and robotics service solutions in the five largest European food markets. In comparison to other national markets, the first limitation recognizes that these are not always the most innovative countries. For example, MMC Ventures (2019) showed that Sweden and Ireland have developed more AI service solutions than Spain and Italy in other sectors. Thus, additional countries should be examined in future to improve the understanding of the European restaurant market. Second, since the US and the Asian markets are more progressive, a comparison with these markets could also be valuable to reflect the technological progress in different business processes. A third limitation refers to the assignment of AI capabilities to the respective AI vendors. Since available corporate websites and online documentation of vendors were analyzed in detail, these AI vendors do not always fully describe the use of AI capabilities, e.g. the use of computer vision in robotics solutions. This implies that specific capabilities could be underestimated in the study and along the same lines the functionalities and capabilities of AI could be differentiated in more detail (e.g. Dietzmann and Alt 2020). Fourth, further biases could have occurred by the effect of AI washing (Domek 2020) that has been observed recently. This signifies that vendors present their solution as AI technology for marketing purposes although they have solely developed single rule-based systems.

Besides the supplier side, restaurant operators should also be interviewed to collect data on the demand side, similar to the work of Neary et al. 2018. Finally, the completeness and usefulness of the reference process should be assessed in detail and challenged by service operators that could test and take advantage of the reference process. Due to its strong organizational focus, other significant aspects related to AI and robotics have not yet been considered and should be added in future development cycles, e.g. the availability of data for AI services (Hofmann et al. 2020) or topics, such as data security, data privacy issues, or the quality of algorithms (e.g. Berezina et al. 2019).

Funding Open Access funding enabled and organized by Projekt DEAL. 


\section{Appendix}

Table 9 The task descriptions are based on the O*NET database with about 1000 job and task descriptions (c.f. Huang et al. 2019).

Business process: customer operations

Subprocess

Customer Information

Customer service and complain management

Order taking (inhouse)

Serving

Consulting/selling

Payment

Online delivery management (order taking \& management)

Capacity \& queue management

Business process: reputation management

Subprocess

Review management (search \& reply)

Business process: supply chain management Subprocess

Procurement planning

Distributor price negotiation

Order/procurement management
Tasks

Level of

intelligence

Getting information (me), processing information (th), evaluating information to determine compliance with standards (th), communicating with persons outside the organization (em)

Mechanical (me) and thinking (th)

Processing information (th), evaluating information to determine compliance with Thinking (th) and standards (th), making decisions and solving problems (th), interpreting the meaning of information for others (th), communicating with persons outside the organization (em), establishing and maintaining interpersonal relationships (em)

Getting information (me), interpreting the meaning of information for others (th), documenting/recording information (me), performing administrative activities (me), monitor processes, materials or surroundings (th)

Performing general physical activity (me), handling and moving objects (me), operating equipment (me)

Thinking creatively (th), developing objectives and strategies (th), interpreting the meaning of information for others (th), provide consultation and advice to other (th), communicating with persons outside the organization (em), resolving conflicts and negotiating with others (em), selling or influencing others (em), establishing and maintaining interpersonal relationships (em)

Performing administrative activities (me), documenting/recording information (me)

Getting information (me), processing information (th), performing administrative activities (me)

Getting information (me), controlling machines and processes (me), documenting/recording information (me), monitor processes, materials, or surroundings (th), identifying objects, actions, and events (th), estimating the quantifiable characteristics of products, events, or information (th), processing information (th), evaluating information to determine compliance with standards (th), updating and using relevant knowledge (th), communicating with persons outside organization (em)

Tasks

Level of intelligence

Getting information (me), interpreting the meaning of information for others (th), Thinking (th) and estimating the quantifiable characteristics of products, events or information (th), processing information (th), analyzing data or information (th), communicating with persons outside organization (em), establishing and maintaining interpersonal relationships (em)

Tasks

Scheduling work and activities (me), organizing, planning and prioritizing work (th), performing administrative activities (me), estimating the quantifiable characteristics of products, events or information (th), updating and using relevant knowledge (th), developing objectives and strategies (th)

Analyzing data or information (th), communicating with persons outside organization (em), negotiating with others (em), resolving conflicts (em)

Performing administrative activities (me), controlling machines and processes (me), inspecting equipment, structures, or material (me),

documenting/recording information (me), handling and moving objects (me), communicating with persons outside organization (em)
Level of intelligence

Mechanical (me) (th) emotional (em)

Mechanical (me) and thinking

Thinking (th) and 
Table 9 (continued)

Inventory management incl. planning and Getting information (me), updating and using relevant knowledge (th), controlling \& food waste management documenting/recording information (me), monitoring and controlling resources (th), processing information (th), analyzing data or information (th), monitoring and controlling resources (th), inspecting equipment, structures or materials (me), estimating the quantifiable characteristics of products, events or information (th)

Hygiene, quality \& food security control Getting information (me), inspecting equipment or material(me), controlling machines and processes (me), documenting/recording information (me), evaluating information to determine compliance with standards (th)

Business process: food \& beverages preparation

Subprocess Tasks

Level of

Recipe creation \& menu planning

Thinking creatively (th), updating and using relevant knowledge (th), monitoring intelligence

Cooking \& drinks and controlling resources (th)

Performing general physical activity (me), handling and moving objects (me), operating devices, operating equipment (me)

Kitchen device management Inspecting equipment, structures or materials (me), controlling machines and processes (me), repairing and maintaining equipment (me), interacting with computers (th)

Mechanical (me) and thinking

\section{Mechanical (me)}

Thinking (th)

Mechanical (me)

Mechanical (me)

Business Process: Management: Business \& Finance

Subprocess Tasks

Business strategy

Monitor processes, materials or surroundings (th), processing information (th), organizing, planning and prioritizing work (th), judging the qualities of things, services or people (th), updating and using relevant knowledge (th), developing objectives and strategies (th), communicating with supervisors, peers or subordinates (em), guiding, directing and motivating subordinates (em), staffing organizational units (em)

Forecasting \& planning Getting information (me), scheduling work and activities (me), organizing, planning and prioritizing work (th), estimating the quantifiable characteristics of products, events or information (th), updating and using relevant knowledge (th), developing objectives and strategies (th), updating and using relevant knowledge (th)

Controlling \& reporting

Documenting/recording information (me), monitor processes (th), analyzing data or information (th), updlang and using relevant knowledge (th), an information (th), monitoring and controlling resources (th)

Accounting Getting information (me), documenting/recording information (me), performing administrative activities (me), processing information (th), monitoring and controlling resources (th)

Business process: reservation Subprocess

Tasks

Table management

Reservation retrieval

Processing information scheduling work and activities (me), planning and prioritizing work (th), estimating the quantifiable characteristics of products, events, or information (th)

Getting information (me), documenting/recording information (me), performing administrative activities (me), communicating with people outside the organization (em)

Business process: marketing

Subprocess

Tasks

Segmentation

Campaign \& promotion planning

Design

Campaign execution (across channels, e.g. social media, email, etc.)

Menu design

Analyzing data or information (th), processing information (th)

Developing objectives and strategies (th), organizing, planning and prioritizing work (th), performing administrative activities (me), documenting/recording information (me)

Thinking creatively (th)

Scheduling work and activities (me), performing administrative work (me),

documenting/recording information (me)

Documenting/recording information (me), thinking creatively (th)

Level of

intelligence

Thinking (th) and

emotional (em)

Mechanical (me) and thinking (th)

Mechanical (me) and thinking (th)

Mechanical (me)

Level of intelligence Thinking (th)

Mechanical (me)

Level of intelligence Thinking (th) Mechanical (me) and thinking (th)

Thinking (th) Mechanical (me)

Mechanical (me) and thinking (th) 
Table 9 (continued)

Business process: human resource management

Subprocess Tasks

Recruiting Getting information (me), scheduling work and activities/ performing administrative activities (me), processing information (th), interpreting the meaning of

Level of

intelligence

Mechanical (me)

and thinking (th) information for others (th), judging the qualities of things, services or people (th), making decisions and solving problems (th), communicating with persons outside the organization (em), staffing organizational units (em)

Staff planning and scheduling

Getting information (me), scheduling work and activities (me), performing administrative activities (me), estimating the quantifiable characteristics of products, events or information (th), organizing, planning and prioritizing work (th), updating and using relevant knowledge (th), coordinating the work and activities of others (em), communicating with supervisors, peers or subordinates (em)

Staff training and development Coaching and developing others (em), training and teaching others (em), development and building teams (em), establishing and maintaining interpers relationships (em), processing information (th), judging the qualities of things, services or people (th), provide consultation and advice to other (th), communicating with supervisors, peers or subordinates (em), guiding, directing and motivating subordinates (em), staffing organizational units (em)

Incident management
Monitor processes, materials or surroundings (th), processing information (th), evaluating information to determine compliance with standards (th), resolving conflicts and negotiating with others (em), making decisions and solving problems (th), provide consultation and advice to other (th), communicating with supervisors, peers or subordinates (em),
Open Access This article is licensed under a Creative Commons Attribution 4.0 International License, which permits use, sharing, adaptation, distribution and reproduction in any medium or format, as long as you give appropriate credit to the original author(s) and the source, provide a link to the Creative Commons licence, and indicate if changes were made. The images or other third party material in this article are included in the article's Creative Commons licence, unless indicated otherwise in a credit line to the material. If material is not included in the article's Creative Commons licence and your intended use is not permitted by statutory regulation or exceeds the permitted use, you will need to obtain permission directly from the copyright holder. To view a copy of this licence, visit http://creativecommons.org/licenses/by/4.0/.

\section{References}

Adam, M., Wessel, M., \& Benlian, A. (2020). AI-based chatbots in customer service and their effects on user compliance. Electronic Markets, 1-19. https://doi.org/10.1007/s12525-020-00414-7.

Acosta, L., González, E. J., Rodríguez, J. N., Hamilton, A. F., Méndez, J. A., Hernéndez, S., Sigut, M., \& Marichal, G. N. (2006). Design and implementation of a service robot for a restaurant. International Journal of Robotics and Automation, 21(4). https://doi.org/10. 2316/Journal.206.2006.4.206-2909.

Aguilar, E., Remeseiro, B., Bolanos, M., \& Radeva, P. (2018). Grab, pay, and eat: Semantic food detection for smart restaurants. IEEE Transactions on Multimedia, 20(12), 3266-3275. https://doi.org/ 10.1109/TMM.2018.2831627.
Allmendinger, G., \& Lombreglia, R. (2005). Four strategies for the age of smart services. Harvard Business Review, 83(10), 131-4, 136, 138 passim.

Alsheibani, S., Messom, C., \& Cheung, Y. (2020). Re-thinking the competitive landscape of artificial intelligence. In T. Bui (Ed.), Proceedings of the 53rd Hawaii international conference on system sciences. https://doi.org/10.24251/HICSS.2020.718.

Alt, R. (2006). Business network redesign-overview of methodologies and example of process portals. Business process transformation (Markus, LM, Grover, V., series: Advances in management information systems, ME Sharpe).

Alt, R. (2020). Evolution and perspectives of electronic markets. Electronic Markets, 30(1), 1-13.

Bardzil, P., \& Slaski, M. (2003). Emotional intelligence: Fundamental competencies for enhanced service provision. Managing Service Quality: An International Journal, 13(2), 97-104. https://doi.org/ 10.1108/09604520310466789.

Bartneck, C., Kulić, D., Croft, E., \& Zoghbi, S. (2009). Measurement instruments for the anthropomorphism, Animacy, likeability, perceived intelligence, and perceived safety of robots. International Journal of Social Robotics, 1(1), 71-81. https://doi.org/10.1007/ s12369-008-0001-3.

Beck, M., \& Libert, B. (2017). The rise of AI makes emotional intelligence more important. Harvard Business Review 15 (2017).

Belanche, D., Casaló, L. V., Flavián, C., \& Schepers, J. (2020). Service robot implementation: A theoretical framework and research agenda. The Service Industries Journal, 40(3-4), 203-225. https://doi. org/10.1080/02642069.2019.1672666.

Beldona, S., \& Kher, H. V. (2015). The impact of customer sacrifice and attachment styles on perceived hospitality. Cornell Hospitality Quarterly, 56(4), 355-368. https://doi.org/10.1177/ 1938965514559048. 
Berezina, K., Ciftci, O., \& Cobanoglu, C. (2019). Robots, artificial intelligence, and service automation in restaurants. In K. Berezina, O. Ciftci, \& C. Cobanoglu (Eds.), Robots, artificial intelligence, and service automation in travel. Tourism and Hospitality: Emerald Publishing Limited. https://doi.org/10.1108/978-1-78756-687320191010 .

Bock, D. E., Wolter, J. S., \& Ferrell, O. C. (2020). Artificial intelligence: Disrupting what we know about services. Journal of Services Marketing, 34(3), 317-334. https://doi.org/10.1108/JSM-01-20190047.

Bryman, A. (2012). Social research methods. Oxford University Press.

Brynjolfsson, E., \& McAfee, A. (2011). Race against the machine: How the digital revolution is accelerating innovation, driving productivity, and irreversibly transforming employment and the economy. Digital Frontier Press.

Buchanan, B. G. (1986). Expert systems: Working systems and the research literature. Expert Systems, 3(1), 32-50. https://doi.org/10. 1111/j.1468-0394.1986.tb00192.x.

Bughin, J., Seong, J., Manyika, J., Chui, M., \& Joshi, R. (2018). Notes from the AI frontier: Modeling the impact of AI on the world economy. https://www.mckinsey.com/featured-insights/artificialintelligence/notes-from-the-ai-frontier-modeling-the-impact-of-aion-the-world-economy. Accessed 01 Sept 2020.

Buhalis, D., \& Law, R. (2008). Progress in information technology and tourism management: 20 years on and 10 years after the internetThe state of eTourism research. Tourism Management, 29(4), 609 623. https://doi.org/10.1016/j.tourman.2008.01.005.

Cain, L. N., Thomas, J. H., \& A Jr., M. (2019). From sci-fi to sci-fact: The state of robotics and AI in the hospitality industry. Journal of Hospitality and Tourism Technology, 10(4), 624-650. https://doi. org/10.1108/JHTT-07-2018-0066.

Cavusoglu, M. (2019). An analysis of technology applications in the restaurant industry. Journal of Hospitality and Tourism Technology, 10(1), 45-72. https://doi.org/10.1108/JHTT-12-20170141.

CB Insights. (2020). AI 100: The artificial intelligence startups redefining industries. https://www.cbinsights.com/research/artificialintelligence-top-startups/. Accessed 01 Sept 2020.

Chen, H.-I. (2019). A conceptual model of profitability determinants in online deal promotions for online-to-offline restaurant merchants. Cluster Computing, 22(4), 10085-10093. https://doi.org/10.1007/ s10586-017-1104-0.

Christ-Brendemühl, S., \& Schaarschmidt, M. (2019). Frontline backlash: Service employees' deviance from digital processes. Journal of Services Marketing, 33(7), 936-945. https://doi.org/10.1108/JSM03-2019-0125.

Chui, M., Manyika, J., \& Miremadi, M. (2015). Four fundamentals of workplace automation. https://www.mckinsey.com/businessfunctions/mckinsey-digital/our-insights/four-fundamentals-ofworkplace-automation

Chui, M., Manyika, J., \& Miremadi, M. (2016). Where machines could replace humans - and where they can't (yet). https://www. mckinsey.com/business-functions/mckinsey-digital/our-insights/ Where-machines-could-replace-humans-and-where-they-cant-yet,

Claveau, D., \& Force, S. (2019). A Mobile social Bar table based on a retired security robot. In J, H. Kim, H. Myung, J. Kim, W. Xu, E, T. Matson, J, W. Jung, \& H, L. Choi (Eds.), Advances in intelligent systems and computing: Vol. 751, robot intelligence technology and applications 5: Results from the 5th international conference on robot intelligence technology and applications (pp. 263-271). Springer International Publishing.

Claypo, N., \& Jaiyen, S. (2014). Opinion mining for Thai restaurant reviews using neural networks and mRMR feature selection. In 2014 international computer science and engineering conference (ICSEC): July 30, 2014 - Aug. 1, 2014, Khon Kaen (pp. 394 397). IEEE. https://doi.org/10.1109/ICSEC.2014.6978229.
Cohen, J. (1960). A coefficient of agreement for nominal scales Educ Psychol Meas: Educ. Psychol. Meas., 20, 37-46.

Cortez, P., Moro, S., Rita, P., King, D., \& Hall, J. (2018). Insights from a text mining survey on expert systems research from 2000 to 2016. Expert Systems, 35(3). https://doi.org/10.1111/exsy.12280.

CUF. (2018). Report: Work to do: How Automation will transform Jobs in NYC. https://nycfuture.org/research/how-automation-willtransform-jobs-in-nyc. Accessed 01 Sept 2020.

Cusumano, M, A., Gawer, A., \& Yoffie, D, B. (2019). The business of platforms: Strategy in the age of digital competition, innovation, and power. Harper Business.

Damanpour, F., \& Gopalakrishnan, S. (2001). The dynamics of the adoption of product and process innovations in organizations. Journal of Management Studies, 38(1), 45-65. https://doi.org/10.1111/14676486.00227.

Davenport, T, H. (1993). Process innovation: Reengineering work through information technology. Harvard Business Review Press.

Davenport, T. H. (2015). Process Management for Knowledge Work. In J. V. Brocke \& M. Rosemann (Eds.), International Handbooks on Information Systems. Handbook on Business Process Management 1: Introduction, Methods, and Information Systems (2nd ed., pp. 17-35). Springer Berlin Heidelberg: Imprint: Springer. https://doi. org/10.1007/978-3-642-45100-3_2.

Davenport, T, H. (2017). When jobs become commodities. MIT Sloan Management Review. https://sloanreview.mit.edu/article/whenjobs-become-commodities

Davenport, T. H. (2018). The AI advantage: How to put the artificial intelligence revolution to work. Management on the cutting edge: The MIT Press.

Davenport, T. H., \& Ronanki, R. (2018). Artificial intelligence for the real world. Harvard Business Review, 96(1), 108-116.

Davenport, T, H., \& Short, J, E. (1990). The new industrial engineering: Information technology and business process redesign.

de Keyser, A., Köcher, S., Alkire, L., Verbeeck, C., \& Kandampully, J. (2019). Frontline service technology infusion: Conceptual archetypes and future research directions. Journal of Service Management, 30(1), 156-183. https://doi.org/10.1108/JOSM-032018-0082.

Dietzmann, C., \& Alt, R. (2020). Assessing the business impact of artificial intelligence: In proceedings of the 53rd Hawaii international conference on system sciences. https://doi.org/10.24251/HICSS. 2020.635

DiPietro, R. (2017). Restaurant and foodservice research: A critical reflection behind and an optimistic look ahead. International Journal of Contemporary Hospitality Management, 29(4), 1203-1234. https://doi.org/10.1108/IJCHM-01-2016-0046 .

Domek, P. (2020). How to invest in AI companies-the case of AI-washing. https://medium.com/swlh/how to-invest-in-ai-companies-thecase-of-ai-washing-1ebfaf038b90.

Eksiri, A., \& Kimura, T. (2015). Restaurant service robots development in Thailand and their real environment evaluation. Journal of Robotics and Mechatronics, 27(1), 91-102. https://doi.org/10. 20965/jrm.2015.p0091.

Evans, D, S., \& Schmalensee, R. (2016). Matchmakers: The new economics of multisided platforms. Harvard Business Review Press.

Ferreira, P., Teixeira, J. G., \& Teixeira, L. F. (2020). Understanding the impact of artificial intelligence on services. In H. Nóvoa, M. Drăgoicea, \& N. Kühl (Eds.), EXPLORING SERVICE SCIENCE: 10th international conference on exploring (pp. 202-213). Springer.

Frey, C. B., \& Osborne, M. A. (2017). The future of employment: How susceptible are jobs to computerisation? Technological Forecasting and Social Change, 114, 254-280. https://doi.org/10.1016/j. techfore.2016.08.019.

Gale, A., \& Mochizuki, T. (2019). Robot hotel loses love for robots. Wall Street Journal. https://www.wsj.com/articles/robot-hotel-loses-lovefor-robots-11547484628 
Gan, Q., Ferns, B. H., Yu, Y., \& Jin, L. (2017). A text mining and multidimensional sentiment analysis of online restaurant reviews. Journal of Quality Assurance in Hospitality \& Tourism, 18(4), 465-492. https://doi.org/10.1080/1528008X.2016.1250243.

Garry, T., \& Harwood, T. (2019). Cyborgs as frontline service employees: A research agenda. Journal of Service Theory and Practice, 29(4), 415-437. https://doi.org/10.1108/JSTP-11-20180241.

Genysis. (2017). Artificial intelligence with the human touch. Blend AI With Human Agents To Improve Both Customer And Agent Satisfaction. https://www.genesys.com/resources/artificialintelligence-with-the-human-touch. Accessed 01 Sept 2020.

Gonzalez, V. C., Torrico, D. D., Dunshea, F. R., \& Fuentes, S. (2019). Emerging technologies based on artificial intelligence to assess the quality and consumer preference of beverages. Beverages, 5(4), 62. https://doi.org/10.3390/beverages5040062.

Govindarajan, M. (2014). Sentiment analysis of restaurant reviews using hybrid classification method of restaurant reviews using hybrid classification method. International Journal of Soft Computing and Artificial Intelligence, 2(1), 17-23.

Gretzel, U. (2011). Intelligent systems in tourism: A social science perspective. Annals of Tourism Research, 38(3), 757-779. https://doi. org/10.1016/j.annals.2011.04.014.

Gretzel, U., Sigala, M., Xiang, Z., \& Koo, C. (2015). Smart tourism: Foundations and developments. Electronic Markets, 25(3), 179188. https://doi.org/10.1007/s12525-015-0196-8.

Groth, M., Wu, Y., Nguyen, H., \& Johnson, A. (2019). The moment of truth: A review, synthesis, and research agenda for the customer service experience. Annual Review of Organizational Psychology and Organizational Behavior, 6(1), 89-113. https://doi.org/10. 1146/annurev-orgpsych-012218-015056.

Gursoy, D., Chi, O. H., Lu, L., \& Nunkoo, R. (2019). Consumers acceptance of artificially intelligent (AI) device use in service delivery. International Journal of Information Management, 49, 157-169. https://doi.org/10.1016/j.ijinfomgt.2019.03.008.

Hambrick, D. C. (1984). Taxonomic approaches to studying strategy: Some conceptual and methodological issues. Journal of Management, 10(1), 27-41. https://doi.org/10.1177/ 014920638401000104.

Harrington, H. J. (1999). Business process improvement: The breakthrough strategy for Total quality, productivity, and competitiveness. New York: McGraw Hill.

Herranz, L., Min, W., \& Jiang, S. (2018). Food recognition and recipe analysis: Integrating visual content, context and external knowledge. CoRR, abs, 1801(07239).

Hofmann, P., Jöhnk, J., Protschky, D., \& Urbach, N. (2020). Developing Purposeful AI Use Cases - A Structured Method and Its Application in Project Management. 15. Internationaler Kongress Für Wirtschaftsinformatik (WI), Potsdam, 9-11 März 2020. https://doi. org/10.30844/wi 2020 a3-hofmann

Hospitality Tech (2018). 7th annual customer engagement technology study 2018: Plugging into the digital minded consumer. Study conducted by: Hospitality Technology: Smarter Hotels and Restaurants.

Huang, M.-H., \& Rust, R. T. (2018). Artificial intelligence in service. Journal of Service Research, 21(2), 155-172. https://doi.org/10. 1177/1094670517752459.

Huang, M.-H., Rust, R., \& Maksimovic, V. (2019). The feeling economy: Managing in the next generation of artificial intelligence (AI). California Management Review, 61(4), 43-65. https://doi.org/10. $1177 / 0008125619863436$

Hull, R., Nezhad, M., \& Hamid R. (2015). Rethinking BPM in a Cognitive World: Transforming how we learn and perform business processes. In International Conference on Business Process Management (pp. 3-19). Cham: Springer.

Hunke, F., Seebacher, S., Schüritz, R., \& Satzger, G. (2020). Pathways from data to value: Identifying strategic archetypes of analytics- based services. 15. Internationaler Kongress Für Wirtschaftsinformatik (WI), Potsdam, 9-11 März 2020. https://doi. org/10.30844/wi_2020 j7-hunke.

IBM. (2015). Cognitive cooking with chef Watson. Recipes for innovation from IBM \& the Institute of Culinary Education. Sourcebooks.

Ivanov, S. (2019). Ultimate transformation: How will automation technologies disrupt the travel, tourism and hospitality industries? Zeitschrift für Tourismuswissenschaft, 11(1), 25-43. https://doi. org/10.1515/tw-2019-0003.

Ivanov, S., \& Webster, C. (Eds.). (2019). Robots, artificial intelligence, and service automation in travel, tourism and hospitality (First ed.). Emerald Publishing Limited.

Ivanov, S., Webster, C., \& Berezina, K. (2017). Adoption of robots, artificial intelligence and service automation by travel, tourism and hospitality companies. Revista Turismo \& Desenvolvimento, 28(27), 1501-1517.

Ivanov, S., Gretzel, U., Berezina, K., Sigala, M., \& Webster, C. (2019). Progress on robotics in hospitality and tourism: A review of the literature. Journal of Hospitality and Tourism Technology, 9074(3), 75. https://doi.org/10.1108/JHTT-08-2018-0087.

Kaplan, J. (2016). Artificial intelligence: What everyone needs to know. Oxford University Press.

Kaplan, A., \& Haenlein, M. (2019). Siri, Siri, in my hand: Who's the fairest in the land? On the interpretations, illustrations, and implications of artificial intelligence. Business Horizons, 62(1), 15-25. https://doi.org/10.1016/j.bushor.2018.08.004.

Kaviya, K., Roshini, C., Vaidhehi, V., \& Sweetlin, J, D. (2017). Sentiment analysis for restaurant rating. In 2017 IEEE international conference on smart technologies and Management for Computing, communication, controls, energy and materials: Icstm: 2nd-4th august: Proceedings (pp. 140-145). IEEE. https://doi.org/10.1109/ ICSTM.2017.8089140.

Kim, H, J., \& Song, M. (2013). An ontology-based approach to sentiment classification of mixed opinions in online restaurant reviews. In a. Jatowt, E.-P. Lim, Y. ding, A. Miura, T. Tezuka, G. Dias, K. Tanaka, A. Flanagin, \& B. T. Dai (Eds.), lecture notes in computer science: Vol. 8238, social informatics: 5th international conference, SocInfo 2013, Kyoto, Japan, November 25-27, 2013, proceedings (pp. 95-108). Springer international publishing; imprint; springer.

Komoguchi, Y., Kunieda, M., \& Yano, K. (2008). Liquid handling control for service robot by hybrid shape approach. In SICE annual conference: 20-22 Aug. 2008, Chofu, Tokyo, Japan. IEEE. https:// doi.org/10.1109/sice.2008.4654945.

Kouvaris, P., Pirogova, E., Sanadhya, H., Asuncion, A., \& Rajagopal, A. (2018). Text enhanced recommendation system model based on yelp reviews. SMU Data Science Review, 1(3).

Kreutzer, R. T., \& Sirrenberg, M. (2020). Understanding artificial intelligence. Springer International Publishing.

Krishna, A., Akhilesh, V., Aich, A., \& Hegde, C. (2019). Sentiment analysis of restaurant reviews using machine learning techniques. In V. Sridhar, M. C. Padma, \& K. A. Rao Radhakrishna (Eds.), Emerging research in electronics, computer science and technology: Proceedings of international conference, ICERECT 2018 (pp. 687-696). Springer.

Kunz, W. H., Heinonen, K., \& Lemmink, J. G. A. M. (2019). Future service technologies: Is service research on track with business reality? Journal of Services Marketing, 33(4), 479-487. https://doi. org/10.1108/JSM-01-2019-0039.

Landis, J. R., \& Koch, G. G. (1977). The measurement of observer agreement for categorical data. Biometrics, 33(1), 159-174. https://doi. org/10.2307/2529310.

Larivière, B., Bowen, D., Andreassen, T. W., Kunz, W., Sirianni, N. J., Voss, C., Wünderlich, N. V., \& de Keyser, A. (2017). "Service encounter 2.0": An investigation into the roles of technology, employees and customers. Journal of Business Research, 79, 238-246. https://doi.org/10.1016/j.jbusres.2017.03.008. 
Lasek, A., Cercone, N., \& Saunders, J. (2016). Restaurant Sales and Customer Demand Forecasting: Literature Survey and Categorization of Methods. In A. Leon-Garcia, R. Lenort, D. Holman, D. Staš, V. Krutilova, P. Wicher, D. Cagáňová, D. Špirková, J. Golej, \& K. Nguyen (Eds.), Lecture Notes of the Institute for Computer Sciences, Social Informatics and Telecommunications Engineering: Vol. 166, Smart City $360^{\circ}$ : First EAI International Summit, Smart City $360^{\circ}$, Bratislava, Slovakia and Toronto, Canada, October 13-16, 2015. Revised Selected Papers (pp. 479-491). Springer International Publishing.

Lee, M, K., Kusbit, D., Metsky, E., \& Dabbish, L. (2015). Working with machines. In B. Begole, J. Kim, K. Inkpen, \& W. Woo (Eds.), Proceedings of the 33rd annual ACM conference on human factors in computing systems (pp. 1603-1612). ACM. https://doi.org/10. 1145/2702123.2702548.

Leon-Garcia, A., Lenort, R., Holman, D., Staš, D., Krutilova, V., Wicher, P., Cagáňová, D., Špirková, D., Golej, J., \& Nguyen, K. (2016) (Eds.). Smart City $360^{\circ}$ : First EAI international summit, Smart City $360^{\circ}$, Bratislava, Slovakia and Toronto, Canada, October 1316, 2015. Revised selected papers. Lecture notes of the Institute for Computer Sciences, social informatics and telecommunications engineering: Vol. 166. Springer International Publishing.

Liu, L.-M., Bhattacharyya, S., Sclove, S. L., Chen, R., \& Lattyak, W. J. (2001). Data mining on time series: An illustration using fast-food restaurant franchise data. Computational Statistics \& Data Analysis, 37(4), 455-476. https://doi.org/10.1016/S0167-9473(01)00014-7.

Lu, V. N., Wirtz, J., Kunz, W. H., Paluch, S., Gruber, T., Martins, A., \& Patterson, P. G. (2020). Service robots, customers and service employees: What can we learn from the academic literature and where are the gaps? Journal of Service Theory and Practice, 30(3), 361391. https://doi.org/10.1108/JSTP-04-2019-0088.

Maier, T., \& Edwards, K. (2020). Service system design and automation in the hospitality sector. Journal of Hospitality, 2(1-2), 1-14.

Marin, J., Biswas, A., Ofli, F., Hynes, N., Salvador, A., Aytar, Y., Weber, I., \& Torralba, A. (2019). Recipe1m+: A dataset for learning crossmodal Embeddings for cooking recipes and food images. IEEE Transactions on Pattern Analysis and Machine Intelligence. https:// doi.org/10.1109/TPAMI.2019.2927476, 1.

Marinova, D., de Ruyter, K., Huang, M.-H., Meuter, M. L., \& Challagalla, G. (2017). Getting Smart. Journal of Service Research, 20(1), 29-42. https://doi.org/10.1177/ 1094670516679273.

Mathath, A., \& Fernando, Y. (2015). Robotic transformation and its business applications in food industry. Robotics, Automation, and Control in Industrial and Service Settings, 281-305.

McClure, P. K. (2018). "You're Fired," Says the Robot. Social Science Computer Review, 36(2), 139-156. https://doi.org/10.1177/ 0894439317698637

Mintel. (2020). US Foodservice Trends 2020. https://www.mintel.com/ foodservice-trends. Accessed 01 Sept 2020.

MMC Ventures. (2019). The State of AI: Divergence. https://www. stateofai2019.com/. Accessed 01 Sept 2020.

Moreno, P., \& Tejada, P. (2019). Reviewing the progress of information and communication technology in the restaurant industry. Journal of Hospitality and Tourism Technology, 10(4), 673-688. https://doi. org/10.1108/JHTT-07-2018-0072 .

Morosan, C. (2011). Customers' adoption of biometric Systems in Restaurants: An extension of the technology acceptance model. Journal of Hospitality Marketing \& Management, 20(6), 661-690. https://doi.org/10.1080/19368623.2011.570645.

Murphy, J., Gretzel, U., \& Pesonen, J. (2019). Marketing robot Services in Hospitality and Tourism: The role of anthropomorphism. Journal of Travel \& Tourism Marketing, 36(7), 784-795. https://doi.org/10. 1080/10548408.2019.1571983.

Nascimento, A, M., Cortez da Cunha, M, A, V., Souza Meirelles, F. de, Scornavacca, E., \& de Melo V. (2018). A literature analysis of research on artificial intelligence in management information system (MIS): Twenty-fourth Americas conference on information systems, New Orleans, 2018.

Neary, B., Horák, J., Kovacova, M., \& Valaskova, K. A. (2018). The future of work: Disruptive business practices, technology-driven economic growth, and computer-induced job displacement. Journal of Self-Governance and Management Economics, 6(4), 19-24.

Nickerson, R. C., Varshney, U., \& Muntermann, J. (2013). A method for taxonomy development and its application in information systems. European Journal of Information Systems, 22(3), 336-359. https:// doi.org/10.1057/ejis.2012.26.

Nonaka, T., Nobutomo, T., \& Mizuyama, H. (2018). A Model of Dynamic Scheduling of Restaurant Operations Considering the Order and Timing of Serving Dishes. In I. Moon, G. M. Lee, J. Park, D. Kiritsis, \& G. von Cieminski (Eds.), IFIP advances in information and communication technology: Vol. 535, Advances in production management systems: Production management for data-driven, intelligent, collaborative, and sustainable manufacturing: IFIP WG 5.7 International Conference, APMS 2018, Seoul, Korea, August 26-30, 2018, Proceedings (pp. 336-341). Berlin: Springer.

Noone, B. M., \& Coulter, R. C. (2012). Applying modern robotics technologies to demand prediction and production Management in the Quick-Service Restaurant Sector. Cornell Hospitality Quarterly, 53(2), 122-133. https://doi.org/10.1177/1938965511434112.

Noone, B. M., \& Maier, T. A. (2015). A decision framework for restaurant revenue management. Journal of Revenue and Pricing Management, 14(4), 231-244. https://doi.org/10.1057/rpm.2015. 15.

Oracle. (2019). Restaurant 2025: Emerging technologies destined to reshape our business. https://www.oracle.com/webfolder/s/delivery production/docs/FY16h1/doc36/Restaurant-2025-OracleHospitality.pdf. Accessed 01 Sept 2020.

Paluch, S., \& Wirtz, J. (2020). Artificial intelligence and robots in the service encounter. SMR. Journal of service management research, 4(1), 3-8. https://doi.org/10.15358/2511-8676-2020-1-3 .

Paluch, S., Wirtz, J., \& Kunz, W. H. (2020). In M. Bruhn, M. Kirchgeorg, \& C. Burmann (Eds.), Service Robots and the Future of Service: in Marketing Weiterdenken - Zukunftspfade für eine marktorientierte Unternehmensführung (2nd ed.). Springer Gabler-Verlag.

Pan, Y. (2016). Heading toward artificial intelligence 2.0. Engineering, 2(4), 409-413. https://doi.org/10.1016/J.ENG.2016.04.018.

Prentice, C. (2014). Who stays, who walks, and why in high-intensity service contexts. Journal of Business Research, 67(4), 608-614.

Prentice, C., Dominique Lopes, S., \& Wang, X. (2020). Emotional intelligence or artificial intelligence- An employee perspective. Journal of Hospitality Marketing \& Management, 29(4), 377-403. https:// doi.org/10.1016/j.jbusres.2013.02.044.

Pumplun, L., Tauchert, C., \& Heidt, M. (2019). A new organizational chassis for artificial intelligence-exploring organizational readiness factors. Proceedings of the 27th European conference on information systems (ECIS) (2019).

Qing-xiao, Y., Can, Y., Zhuang, F., \& Yan-zheng, Z. (2010). Research of the localization of restaurant service robot. International Journal of Advanced Robotic Systems, 7(3), 18. https://doi.org/10.5772/9706 .

Qiu, H., Li, M., Shu, B., \& Bai, B. (2020). Enhancing hospitality experience with service robots: The mediating role of rapport building. Journal of Hospitality Marketing \& Management, 29(3), 247-268. https://doi.org/10.1080/19368623.2019.1645073.

Rafaeli, A., Altman, D., Gremler, D. D., Huang, M.-H., Grewal, D., Iyer, B., Parasuraman, A., \& de Ruyter, K. (2017). The future of frontline research. Journal of Service Research, 20(1), 91-99. https://doi.org/ $10.1177 / 1094670516679275$. 
Ransbotham, D. K., Gerbert, P., \& Reeves, M. (2017). Reshaping business with artificial intelligence: Closing the gap between ambition and action. MIT Sloan Management Review, 59(1).

Remane, G., Nickerson, R., Hanelt, A., Tesch, J., \& Kolbe, L. (2016). A taxonomy of Carsharing business models. ICIS 2016 proceedings.

Rhoades, E. A. (2011). Literature Reviews. The Volta Review, 111(3), 353.

Rosenblat, A., \& Stark, L. (2016). Algorithmic labor and information asymmetries: A case study of Uber's drivers. International Journal of Communication, 10(27). https://doi.org/10.2139/ssrn. 2686227.

Rosete, A., Soares, B., Salvadorinho, J., Reis, J., \& Amorim, M. (2020). Service robots in the hospitality industry: An exploratory literature review. In H. Nóvoa, M. Drăgoicea, \& N. Kühl (Eds.), EXPLORING SERVICE SCIENCE: 10th international conference on exploring (pp. 174-186). Springer.

Russell, S. J., \& Norvig, P. (2016). Artificial intelligence: A modern approach. In Malaysia. Pearson Education: Limited.

Saldaña, J. (2009). An introduction to codes and coding. The coding manual for qualitative researchers, 3 .

Salvador, A., Hynes, N., Aytar, Y., Marin, J., Ofli, F., Weber, I., \& Torralba, A. (2017). Learning cross-modal Embeddings for cooking recipes and food images. In Proceedings of the IEEE Conference on Computer Vision and Pattern Recognition.

Sarvari, P. A., Ustundag, A., \& Takci, H. (2016). Performance evaluation of different customer segmentation approaches based on RFM and demographics analysis. Kybernetes, 45(7), 1129-1157. https://doi. org/10.1108/K-07-2015-0180.

Sato, K., Oka, M., \& Kato, K. (2019). Early Turnover Prediction of New Restaurant Employees from Their Attendance Records and Attributes. In S. Hartmann, J. Küng, S. Chakravarthy, G. AnderstKotsis, A. M. Tjoa, \& I. Khalil (Eds.), Information Systems and Applications, incl. Internet/Web, and HCI: Vol. 11706, Database and Expert Systems Applications: 30th International Conference, DEXA 2019. Linz, Austria, Proceedings, Part I (1st ed., pp. 277286): Springer International Publishing; Imprint: Springer.

Seidel, S., Shortland, K., Court, D., \& Elzinga, D. (2015). Managing Creativity-intensive Processes: Learning from Film and Visual Effects Production. In J. V. Brocke \& M. Rosemann (Eds.), International Handbooks on Information Systems Handbook on Business Process Management 1: Introduction, Methods, and Information Systems (2nd ed., pp. 515-538). Springer Berlin Heidelberg: Imprint: Springer. https://doi.org/10.1007/978-3-64201982-1 24.

Simon, H. A. (1995). Artificial intelligence: an empirical science. Artificial Intelligence, 77(1), 95-127. https://doi.org/10.1016/ 0004-3702(95)00039-H.

Singh, J., Brady, M., Arnold, T., \& Brown, T. (2017). The emergent field of organizational frontlines. Journal of Service Research, 20(1), 3 11. https://doi.org/10.1177/1094670516681513.

Statista. (2017). Turnover of the food and beverage service activities industry in the European Union (EU-28) in 2017, by country. https://www.statista.com/statistics/684161/turnover-of-the-foodbeverage-service-industry-in-the-eu-by-country

Tambe, P., Cappelli, P., \& Yakubovich, V. (2019). Artificial intelligence in human resources management: Challenges and a path forward. California Management Review, 61(4), 15-42. https://doi.org/10. $1177 / 0008125619867910$.

Tan, T. F., \& Staats, B. R. (2020). Behavioral drivers of routing decisions: Evidence from restaurant table assignment. Production and Operations Management, 29(4), 1050-1070. https://doi.org/10. 1111/poms. 13155

Tanizaki, T., Shimmura, T., \& Fujii, N. (2017). Shift scheduling to improve customer satisfaction, employee satisfaction and management satisfaction in service workplace where employees and robots collaborate. In Y. Hara \& D. Karagiannis (Eds.), Lecture notes in computer science: Vol. 10371, Serviceology for services: 5th international conference, ICServ 2017, Vienna, Austria, July 12-14, 2017, proceedings (pp. 15-25). Springer International Publishing.

Tanizaki, T., Hoshino, T., Shimmura, T., \& Takenaka, T. (2019). Demand forecasting in restaurants using machine learning and statistical analysis. Procedia CIRP, 79, 679-683. https://doi.org/10. 1016/j.procir.2019.02.042.

Trantopoulos, K., von Krogh, G., Wallin, M. W., \& Woerter, M. (2017). External knowledge and information technology: Implications for process innovation performance. MIS quarterly, 41(1), 287-300. https://doi.org/10.25300/MISQ/2017/41.1.15.

Turban, E., \& Watkins, P. R. (1986). Integrating expert systems and decision support systems. MIS Quarterly, 10(2), 121. https://doi. org $/ 10.2307 / 249031$

Tussyadiah, I. P., \& Park, S. (2018). Consumer evaluation of hotel service robots. In B. Stangl \& J. Pesonen (Eds.), Information and communication Technologies in Tourism 2018: Proceedings of the international conference in Jönköping, Sweden, January 24-26, 2018 (pp. 308-320). Springer International Publishing.

Tzou, J.-H., \& Kuo, L. S. (2009). High-speed laser localization for a restaurant service Mobile robot. Artificial Life and Robotics, 14(2), 252-256. https://doi.org/10.1007/s10015-009-0665-2.

Un, C. A., \& Asakawa, K. (2015). Types of R\&D collaborations and process innovation: The benefit of collaborating upstream in the knowledge chain. Journal of Product Innovation Management, 32(1), 138-153. https://doi.org/10.1111/jpim.12229.

van Doorn, J., Mende, M., Noble, S. M., Hulland, J., Ostrom, A. L., Grewal, D., \& Petersen, J. A. (2017). Domo Arigato Mr.Roboto. Journal of Service Research, 20(1), 43-58. https://doi.org/10.1177/ 1094670516679272.

Venkatraman, N. (1994). IT-enabled business transformation: From automation to business scope redefinition. Sloan Management Review, $35,73-73$.

Vidotto, A., Brown, K, N., \& Beck, J, C. (2007). Managing restaurant tables using constraints. In R. Ellis, T. Allen, A. Tuson, A. Vidotto, K, N. Brown, \& J, C. Beck (Eds.), Managing restaurant tables using constraints: Applications and innovations in intelligent systems XIV (pp. 3-16). Springer London.

Vom Brocke, J., Zelt, S., \& Schmiedel, T. (2016). On the role of context in business process management. International Journal of Information Management, 36(3), 486-495. https://doi.org/10.1016/ j.ijinfomgt.2015.10.002

Walker, J, R. (2017). Introduction to hospitality (seventh edition, Global Edition). Pearson Education Limited.

Wang, Y., Hu, Z., \& Wang, Y. (2017). The application of Markov decision process in restaurant delivery robot. AIP Conference Proceedings, 1839(1), 20177. https://doi.org/10.1063/1.4982542.

Willcocks, L, P., Lacity, M., \& Craig, A. (2015). The IT function and robotic process automation: The London School of Economics and Political Science. Outsourcing unit working research paper series, paper 15/05, London.

Wirtz, J., Patterson, P. G., Kunz, W. H., Gruber, T., Lu, V. N., Paluch, S., \& Martins, A. (2018). Brave new world: Service robots in the frontline. Journal of Service Management, 29(5), 907-931. https://doi. org/10.1108/JOSM-04-2018-0119 .

World Economic Forum (2018). The Future of Jobs Report 2018.

Wu, H.-C., \& Cheng, C.-C. (2018). What drives experiential loyalty toward smart restaurants? The case study of KFC in Beijing. Journal of Hospitality Marketing \& Management, 27(2), 151-177. https://doi.org/10.1080/19368623.2017.1344952 .

Xinliang, L., \& Dandan, S. (2017). University restaurant sales forecast based on BP neural network - In Shanghai Jiao Tong University case. In Y. Tan, H. Takagi, Y. Shi, \& B. Niu (Eds.), Lecture notes in computer science: Vol. 10386, advances in swarm intelligence: 8 th international conference, ICSI 2017. Fukuoka, Japan, Proceedings, 
part II (pp. 338-347): Springer international publishing; imprint; springer.

Yan, W. X., Fu, Z., Liu, Y. H., Zhao, Y. Z., Zhou, X. Y., Tang, J. H., \& Liu, X. Y. (2007). A novel automatic cooking robot for Chinese dishes. Robotica, 25(4), 445-450. https://doi.org/10.1017/ S0263574706003250.

Yang, L., Henthorne, T. L., \& George, B. (2020). Artificial intelligence and robotics Technology in the Hospitality Industry: Current applications and future trends. In B. George \& J. Paul (Eds.), Digital transformation in business and society: Theory and cases (1st ed., pp. 211-228). Springer International Publishing. https://doi.org/10. 1007/978-3-030-08277-2_13.
Yu, Q., Yuan, C., Fu, Z., \& Zhao, Y. (2012). An autonomous restaurant service robot with high positioning accuracy. Industrial Robot: An International Journal, 39(3), 271-281. https://doi.org/10.1108/ 01439911211217107.

Zebec, A.. (2019). Cognitive BPM: Business Process Automation and Innovation with Artificial Intelligence: In BPM (PhD/Demos) (pp. $51-59)$.

Ziller, A., Hansjakob, J., Rusinov, V., Zügner, D., Vogel, P., \& Günnemann, S. (2019). Oktoberfest Food Dataset.

Publisher's note Springer Nature remains neutral with regard to jurisdictional claims in published maps and institutional affiliations. 